\title{
A Dicopper Dioxygenase Model Immobilized in Mesoporous Silica Nanoparticles for Toluene Oxidation: A Mechanism to Harness Both O Atoms of $\mathrm{O}_{2}$ for Catalysis
}

Chih-Cheng Liu, ${ }^{\dagger}$ Yi-Fang Tsai, ${ }^{\dagger}$ Chung-Yuan Mou, ${ }^{*}{ }^{\star}$ Steve S.-F. Yu, ${ }^{\dagger}$ and Sunney I. Chan ${ }^{*}, \dagger$

\footnotetext{
†Institute of Chemistry, Academia Sinica, No. 128, Sec. 2, Academia Road, Nankang, Taipei 11529, Taiwan

Department of Chemistry, National Taiwan University, No. 1, Sec. 4, Roosevelt Road, Daan District, Taipei 10617, Taiwan

*E-mail: sunneychan@yahoo.com; cymou@ntu.edu.tw
}

\section{Table of Contents}

Materials and Methods

Resonance Raman Spectra of the Dicopper Species

Summary of Best Fits to EXAFS Data

Supporting Figures (Figures S1 to S17)

References 


\section{Material and Methods}

\section{Preparation of the Cu ${ }^{\mathrm{II}} \mathrm{Imph} @ M S N-T P-3$ samples}

Synthesis of the ligand Imph and the $\mathbf{C} \mathbf{u}^{\text {II }} \mathbf{I m p h}$, and X-ray structure of the

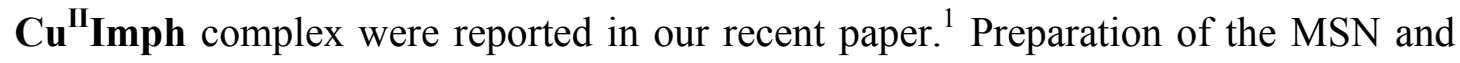

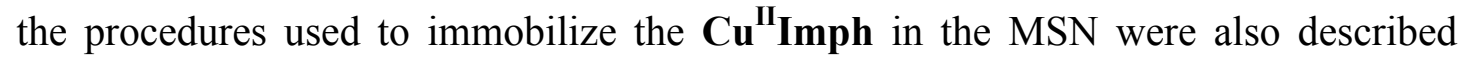
there. ${ }^{1}$ Briefly, the following procedure was used to prepare Cu${ }^{\text {II } I m p h @ M S N-T P-3 . ~}$

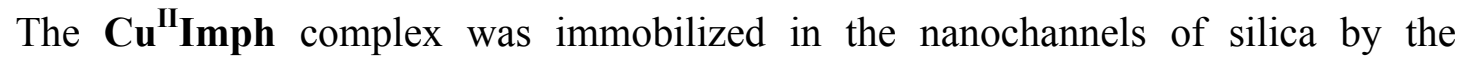
ion-exchange method via electrostatic attraction. To begin, an ion exchange solution

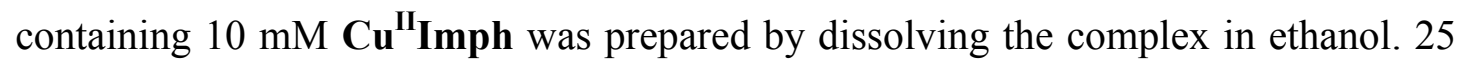
$\mathrm{ml}$ of this solution were then added slowly to $150 \mathrm{mg}$ of freshly prepared MSN well dispersed in $25 \mathrm{ml} 99.5 \%$ ethanol, and the mixture was stirred at $30^{\circ} \mathrm{C}$ for $24 \mathrm{~h}$. The solids were collected by centrifugation, washed by $95 \%$ ethanol, and dried in vacuum. The loading of the copper complex in the nanoparticles was determined by measuring the copper content by ICP-MS and C, N elemental analysis. The amount of $\mathbf{C u}^{\mathrm{II}} \mathbf{I m p h}$ encapsulated by the nanosized MSN-TP-3 sample is $3.23 \times 10^{-4} \mathrm{~mol} \mathrm{~g}^{-1}$. The BET surface area of the CuIIImph@MSN-TP-3 is $630 \mathrm{~m}^{2} \mathrm{~g}^{-1}$ and the BET pore volume is $0.32 \mathrm{~cm}^{3} \mathrm{~g}^{-1}$. The zeta-potential is $-26 \mathrm{mV}$.

\section{Methods of analysis of the CuImph@MSN-TP-3 samples}

The copper contents of the mesoporous materials were analyzed with a simultaneous ICP-MS allied analytical system (Perkin-Elmer, Elan 6000). Elemental analyses for $\mathrm{C}, \mathrm{H}$, and $\mathrm{N}$ were carried out on a Heraeus vario III-NCH microanalyzer. The surface area, pore size, and pore volume of the MSN were determined by $\mathrm{N}_{2}$ adsorption-desorption isotherms obtained at $77 \mathrm{~K}$ on a Micrometric ASAP 2010 apparatus. The sample was outgassed at $2 \times 10^{-3}$ torr and $120^{\circ} \mathrm{C}$ for at least $5 \mathrm{~h}$ prior to the adsorption of the $\mathrm{N}_{2}$. The pore size distribution curves were obtained from the analysis of the adsorption portion of the isotherms using the BJH (Barrett-Joyner-Halenda) method. Zeta potentials were obtained by the averaging of ten measurements. For these experiments, the samples were prepared at the concentration of $2 \mathrm{mg}$ in $1 \mathrm{ml}$ of de-ionized $\mathrm{H}_{2} \mathrm{O}$. Different $\mathrm{pH}$ values were adjusted by the addition of $0.02 \mathrm{M} \mathrm{HCl}_{(\mathrm{aq})}$ or $\mathrm{NaOH}_{(\mathrm{aq})}$. Before measurement, each sample was ultra-sonicated for $5 \mathrm{~min}$ to prevent any aggregation. 
The single-turnover experiment described in the text was repeated with $d_{8}$-toluene.

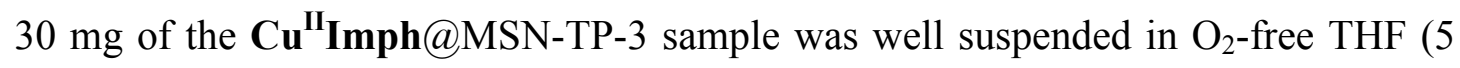
$\mathrm{ml}$ ) in a $10 \mathrm{ml}$ Schlenk flask. After reduction by sodium ascorbate solution, the system was directly vacuum-dried to remove the solvents. Then $5 \mathrm{ml}$ of $\mathrm{O}_{2}$-free THF was added and the system was saturated with $\mathrm{O}_{2}$. The sample was then frozen, and the "excess" $\mathrm{O}_{2}$ was pumped away. After drying and re-purging of the sample with $\mathrm{N}_{2}$ gas for 5 times, the reacting substrate $d_{8}$-toluene $(0.03 \mathrm{ml}$, technical grade) (29 equiv.) was added and the products analyzed periodically by using GC-MS. During the burst phase, when the initial $d_{8}$-benzyl alcohol ( $d_{7}$-BnOD) was formed, the production of any $\mathrm{D}_{2} \mathrm{O}$ was also monitored. Subsequently, the sample was incubated at room temperature and the products analyzed for $d_{8}$-benzyl alcohol, $d_{6}$-benzaldehyde, and $\mathrm{D}_{2} \mathrm{O}$ at various time intervals by GC-MS.

\section{GC-MS analysis of the products}

The products of the toluene and $d_{8}$-toluene oxidation reaction were analyzed by GC-MS and confirmed by comparing with commercially available authentic standards (toluene, benzyl alcohol, and benzaldehyde) and the built-in MS database software (Figure S11: benzyl alcohol; Figure S12: benzaldehyde; Figure S13: $d_{8}$-benzyl alcohol; Figure S14: $d_{6}$-benzaldehyde; and Figure S15: $\left.\mathrm{D}_{2} \mathrm{O}\right)$. The yields of the corresponding products were calculated on the basis of comparisons to a series of calibration curves for each of the authentic standard compounds; externally added decane was used as an internal standard.

All GC-MS experiments were performed using a Clarus 600/560D gas chromatograph-mass spectrometer. The GC-MS conditions for the product analysis were as follows: Injector port temperature: $180{ }^{\circ} \mathrm{C}$; Column: initial temperature, $85{ }^{\circ} \mathrm{C}$ (hold for $2 \mathrm{~min}$ ); gradient rate, $15^{\circ} \mathrm{C} / \mathrm{min}(6 \mathrm{~min})$; final temperature, $175{ }^{\circ} \mathrm{C}$; flow, $200 \mathrm{ml} / \mathrm{min}$.

\section{UV-Visible spectra of the MSN samples}

Reduction of the immobilized $\mathbf{C u}$ II Imph $(1.34 \mu \mathrm{mol})$ was performed by the addition of sodium ascorbate to the CuIIImph@MSN-TP-3 sample to generate the CuIImph@MSN-TP-3 sample in situ under a $\mathrm{N}_{2}$ atmosphere. The heterogeneous mixture was then directly vacuum-dried, and the solid samples of the CuIImph@MSN-TP-3 were exposed to $\mathrm{O}_{2}$ at room temperature. A significant absorption band at $390 \mathrm{~nm}$ was observed in the UV-Visible spectrum. 
After the formation of the species $1,5 \mathrm{ml} \mathrm{O}_{2}$-free THF was added to the solid sample to obtain a high-quality suspension. The mixture was frozen and the "excess" $\mathrm{O}_{2}$ in the system was pumped away by vacuum drying and re-purging with $\mathrm{N}_{2}$ gas for 5 times. $0.03 \mathrm{ml}$ of the reacting substrate toluene (technical grade) (29 equiv.) was then added to the system and the reaction was followed for $2 \mathrm{~h}$ at room temperature. After performing a single-turnover experiment under $\mathrm{O}_{2}$-limiting conditions, the $\mu$-oxo-dicopper(II) species (species 2) was formed, with significant UV-Visible absorptions observed at $300 \mathrm{~nm}$ and $642 \mathrm{~nm}$.

After the formation of the species 2, the mixture was directly vacuum-dried overnight to remove the solvent, the toluene substrate, the product benzyl alcohol, and all the $\mathrm{O}_{2}$ in the sample, including any $\mathrm{O}_{2}$ that might be trapped in the micropores of the Cu-complex-loaded MSN. Then THF was added to the solid sample to obtain a high-quality suspension and $\mathrm{O}_{2}$ was introduced to activate species 2 to form the species 3 under a substrate-free condition. Two intense bands at $390 \mathrm{~nm}$ and $516 \mathrm{~nm}$ emerged in the UV-Visible spectrum, together with a weaker feature at $626 \mathrm{~nm}$. The spectrum was sensitive to UV light. The time course of the decay of the light-sensitive species 3 was performed by exposure of the sample to UV-Visible light for $5 \mathrm{~s}$ (red, Figure $4 \mathrm{~d}$ ), and $15 \mathrm{~s}$ (blue, Figure 4d) during successive scanning of the sample to obtain the UV-Visible spectrum.

UV-Visible spectra of the MSN samples were taken with a Hitachi U-3010 spectrophotometer. The spectra were collected in the wavelength range of 300-800 nm against a standard.

\section{Raman spectra of the MSN samples}

Raman data obtained by excitation at $473 \mathrm{~nm}$ were performed by Professor I-Chia Chen and Mr. Bo-Han Wu in the Department of Chemistry at National Tsing Hua University in Hsinchu, Taiwan. The Raman spectra were recorded in a backscattering geometry employing an objective lens $(10 \times)$. A diode-pumped Nd:YAG laser (Photop Suwtech) laser operating with blue light at $473 \mathrm{~nm}$ served as the excitation light source. The laser power at the sample region was set at $10 \mathrm{~mW}$. The scattered signal passing through an edge filter, optical fiber, and monochromator (length, $0.5 \mathrm{~m}$; grating 600 grooves/mm) was recorded with a liquid-nitrogen-cooled charge-coupled device (CCD) detector. 
Raman spectra obtained with laser excitation at $325 \mathrm{~nm}$ were collected using a LabRam HR800 confocal microprobe Raman instrument (HORIBA Jobin Yvon, France) by Dr. Lin Li at the Dalian Institute of Chemical Physics, Chinese Academy of Sciences, Dalian 116023, China.

Raman spectra recorded with laser excitation at $532 \mathrm{~nm}$ were collected using a He-Ne laser at room temperature on a Horiba Jobin-Yvon LabRam HR800 instrument by Dr. Yi-Chia Luo and Dr. Li-Chyong Chen at the Center for Condensed Matter Sciences (CCMS) at National Taiwan University, Taipei, Taiwan.

\section{EPR experiments}

EPR spectra were recorded on a Bruker E-500 spectrometer equipped with a Bruker TE102 cavity. The sample temperature was maintained at $77 \mathrm{~K}$ by immersion of the EPR sample tube into a liquid $\mathrm{N}_{2}$ cold finger dewar. Typical EPR measurement conditions were as follows: microwave frequency, $9.4 \mathrm{GHz}$; microwave power, 19.21 $\mathrm{mW}$; modulation frequency, $100 \mathrm{kHz}$; modulation amplitude, $10 \mathrm{G}$; receiver gain, 2000; conversion time, $20.48 \mathrm{~ms}$; time constant, $20.48 \mathrm{~ms}$. EPR spectra were simulated using the Simfonia program to obtain the $g$ values and A values.

\section{EXAFS analysis}

Data reduction of the X-ray absorption spectra included energy calibration assigning the first inflection point of the $\mathrm{Cu}$ foil to $8,979.0 \mathrm{eV}$, pre-edge subtraction using a polynomial function, spline removal, and normalization. EXAFS spectra were extracted from the experimentally measured absorption coefficient in the EXAFS region after background subtraction and normalization methods implemented in the program ATHENA. ${ }^{2}$ For fitting of the experimental EXAFS data, a nonlinear least-square fitting algorithm implemented by the IFEFFIT program was employed. ${ }^{3}$ Best fits of the Fourier-filtered EXAFS spectra $\left(\mathrm{k}^{3} \chi(\mathrm{k})\right)$ were used to deduce the ligand structures of the $\mathrm{Cu}$ ions in each of the species, including both the first- and second-coordination spheres. Data fitting quality was evaluated by the goodness-of-fit factor defined as follow: 
$\mathrm{R}_{\mathrm{fit}}=\frac{\sum_{i=1}^{n}\left\{\left[\operatorname{Re}\left(f_{i}\right)^{2}\right]+\left[\operatorname{Im}\left(f_{i}\right)\right]^{2}\right\}}{\sum_{i=1}^{n}\left\{\left[\operatorname{Re}\left(\tilde{\chi}_{\text {data }}\right)\right]^{2}+\left[\operatorname{Im}\left(\widetilde{\chi}_{\text {data }}\right)\right]^{2}\right\}}$, where $\tilde{\chi}=k^{3} \chi$ and $\mathrm{n}$ is the number of evaluations of $f_{i}$, with $f_{i}=\tilde{\chi}_{\text {data i }}-\tilde{\chi}_{\text {model i }}$ (and hence $\mathrm{R}_{\text {fit }}$ ) minimized in the nonlinear least-square fitting algorithm. ${ }^{4}$

\section{Resonance Raman Spectra of the Dicopper Species}

We have made numerous attempts to record resonance Raman (rR) spectra of the various dicopper species in the MSN-TP-3 to observe the symmetric $\mathrm{Cu}-\mathrm{O}-\mathrm{Cu}$ and $\mathrm{O}-\mathrm{O}$ vibrations but without success. To resonance enhance these vibrations it is necessary to excite the LMCT transitions of the dicopper complexes in these MSNs in the vicinity of 300-390 $\mathrm{nm}$. Unfortunately, the MSN-TP-3 sample quickly deteriorates (within $20 \mathrm{sec}$ ) during these measurements, presumably due to laser heating, even when the Raman experiments are performed at $77 \mathrm{~K}$ (laser excitation at both $325 \mathrm{~nm}$ and $473 \mathrm{~nm}$ ). To illustrate this technical difficulty, we compare in Figure S16 the

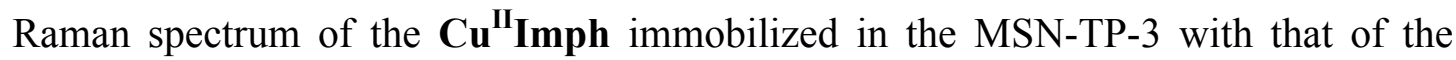

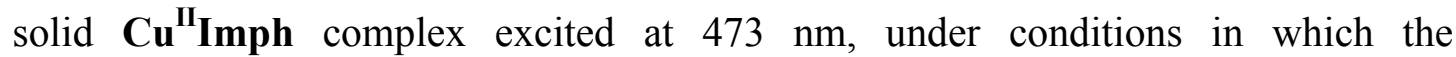
Raman-active ligand vibrations of the $\mathrm{Cu}^{\mathrm{II}}$ complex would be resonance enhanced. We also show the Raman spectrum of species 1 obtained by laser excitation for $20 \mathrm{sec}$ at $473 \mathrm{~nm}$ at $77 \mathrm{~K}$, in which only a strong background is observed from 200-1400 $\mathrm{cm}^{-1}$ and no characteristic peaks can be identified. In contrast to the high-quality rR spectrum of the $\mathbf{C} \mathbf{u}^{\mathrm{II}} \mathbf{I m p h}$ complex in the solid, the Raman scattering from vibrations of the silica framework in the MSN-TP-3 is so strong that the silicate bands mask the

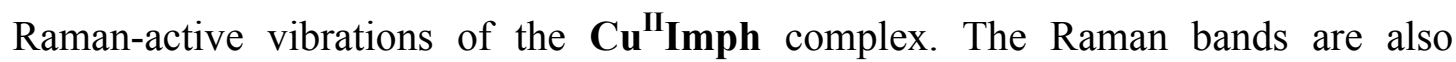
broadened due to the laser heating of the nanoparticles. With time (20 sec), only Rayleigh light scattering is observed, indicating deterioration of the sample. As a control, we show Raman spectra collected using laser excitation at the longer wavelength of $532 \mathrm{~nm}$ on samples of (a) bare-MSN; (b) MSN-TP-3; (c) Cu'Imph@MSN-TP-3; and (d) $\left[\left\{\mathbf{C} \mathbf{u}^{\text {III } I m p h}\right\}_{2}\left(\mu-\mathrm{O}^{2-}\right)_{2}\right]^{2+} @$ MSN-TP-3 in Figure S17. No laser heating of the nanoparticles is noted here, but it is also evident that the silicate vibrations dominate the Raman scattering so that it would be difficult to discern the dicopper oxo-core vibrations of interest even when they were resonance enhanced. In any case, the light sensitivity of species $\mathbf{3}$ precludes us from addressing the structure/bonding of the $\mathrm{O}_{2}$-adduct and its involvement in the catalytic cycle by conventional rR spectroscopy. 


\section{Summary of Best Fits to EXAFS Data}

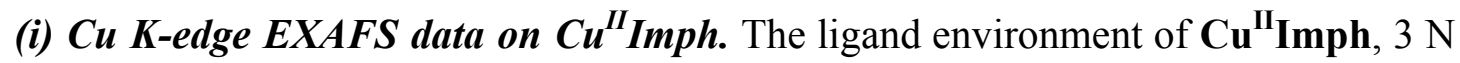
at $1.95 \AA, 1 \mathrm{~N}$ at $2.08 \AA$ (Figure $7 \mathrm{a}$ and Table $2 \mathrm{a}$ ), is in excellent agreement with the $\mathrm{X}$-ray structure of the complex in the crystal $\left(2 \mathrm{~N}\right.$ with an average $\mathrm{Cu}-\mathrm{N}_{\text {im }}$ bond distance of $1.927 \AA, 1 \mathrm{~N}$ with a $\mathrm{Cu}-\mathrm{N}_{\mathrm{CH} 3 \mathrm{CN}}$ distance of $1.982 \AA$, and $1 \mathrm{~N}$ with a $\mathrm{Cu}-\mathrm{N}_{\text {amine }}$ bond distance of $2.072 \AA$ ), previously reported by us. ${ }^{1}$

(ii) Cu K-edge EXAFS data on species 1. The Cu EXAFS data obtained for species 1 (Figure $7 \mathrm{~b}$ and Table $2 \mathrm{~b}$ ) are consistent with the $\mathrm{Cu}^{\mathrm{III}}(\mu-\mathrm{O})_{2} \mathrm{Cu}^{\mathrm{III}}$ intermediate, with a ligand environment for the bis( $\mu$-oxo)dicopper species consisting of $3 \mathrm{~N}$ at an average distance of $1.96 \AA, 2 \mathrm{O}$ at $1.91 \AA, 7 \mathrm{C}$ at $3.15 \AA$, and backscattering by $1 \mathrm{Cu}$ at a distance of $2.65 \AA$. The average $\mathrm{Cu}-\mathrm{N}$ distance in the $\mathrm{Cu}^{\mathrm{III}}(\mu-\mathrm{O})_{2} \mathrm{Cu}^{\mathrm{III}}$ species is similar to that in the mononuclear $\mathbf{C} \mathbf{u}^{\mathrm{II}} \mathbf{I m p h}$, but the average $\mathrm{Cu}-\mathrm{C}$ distance has increased from $3.05 \AA$ to $3.15 \AA$. For comparison, the $\mathrm{Cu}{ }^{\cdots} \mathrm{Cu}(2.65 \AA)$ is somewhat shorter here relative to other $\mathrm{Cu}^{\mathrm{III}}(\mu-\mathrm{O})_{2} \mathrm{Cu}^{\mathrm{III}}$ complexes $(\sim 2.70 \AA)^{5}$ and the average $\mathrm{Cu}-\mathrm{O}$ distance $(1.91 \AA)$ is slightly longer than in other dicopper complexes $(\sim 1.8 \AA),{ }^{5}$ reflecting the confinement effect on the structure of the activated dicopper cluster within the nanochannels of the silica.

(iii) Cu K-edge EXAFS data on species 2. The Cu EXAFS data obtained for species 2 (Figure $7 \mathrm{c}$ and Table $2 \mathrm{c}$ ) reveal a $\mathrm{Cu}(\mathrm{II})$ species with $3 \mathrm{~N}$ with an average $\mathrm{Cu}-\mathrm{N}$ bond distance of $1.97 \AA, 1 \mathrm{O}$ with a $\mathrm{Cu}-\mathrm{O}$ distance of $1.89 \AA, 7 \mathrm{C}$ at a distance of $3.14 \AA$, and backscattering from $1 \mathrm{Cu}$ at a distance of $2.84 \AA$, consistent with the formation of a $\mathrm{Cu}^{\mathrm{II}}(\mu-\mathrm{O}) \mathrm{Cu}^{\mathrm{II}}$ species. For comparison, the average $\mathrm{Cu}-\mathrm{N}$ and $\mathrm{Cu}-\mathrm{C}$ distances in the $\mathrm{Cu}^{\mathrm{II}}(\mu-\mathrm{O}) \mathrm{Cu}^{\mathrm{II}}$ species 2 are almost identical to the corresponding distances in the $\mathrm{Cu}^{\mathrm{III}}(\mu-\mathrm{O})_{2} \mathrm{Cu}^{\mathrm{III}}$ species 1 . The $\mathrm{Cu}^{\cdots} \mathrm{Cu}$ distance in the $\mathrm{Cu}^{\mathrm{II}}(\mu-\mathrm{O}) \mathrm{Cu}^{\mathrm{II}}$ species $2(2.84 \AA)$ is slightly shorter than the corresponding distance $(2.91 \AA)$ reported by Limberg et al. ${ }^{6}$ in the $[\mathrm{FurNeu}]\left(\mathrm{Cu}_{2}(\mu-\mathrm{O})\right)(\mathrm{OTf})_{2}$ complex.

(iv) Cu K-edge EXAFS data on species 3. The EXAFS data obtained for species 3 (Figure $7 \mathrm{~d}$ and Table $2 \mathrm{~d}$ ) show an additional $\mathrm{O}(1)$ in the first coordination sphere of each $\mathrm{Cu}$ ion, namely, $2 \mathrm{Cu}-\mathrm{O}$ with average bond distance of $1.93 \AA$, and a third $\mathrm{O}(2)$ in the second coordination sphere with a bond distance of $2.93 \AA$, together with lengthening of the $\mathrm{Cu} \cdots \mathrm{Cu}$ distance to $3.64 \AA$. These results are consistent with the 
structure of the $\mathrm{O}_{2}$ adduct proposed for the copper cluster in the putative $\mathrm{Cu}^{\mathrm{III}}(\mu-\mathrm{O})((\mu-1,2)-$ peroxo $) \mathrm{Cu}^{\mathrm{III}}$ species 3. In this species, the average $\mathrm{Cu}-\mathrm{N}$ and $\mathrm{Cu}-\mathrm{C}$ distances are $1.97 \AA$ and $3.15 \AA$, respectively, similar to the corresponding distances in $\mathrm{Cu}^{\mathrm{III}}(\mu-\mathrm{O}){ }_{2} \mathrm{Cu}^{\mathrm{III}}$ species $\mathbf{1}$ and $\mathrm{Cu}^{\mathrm{II}}(\mu-\mathrm{O}) \mathrm{Cu}^{\mathrm{II}}$ species 2 . Interestingly, the $\mathrm{Cu}^{\cdots} \mathrm{Cu}$ and $\mathrm{Cu}-\mathrm{O}(1)$ distances from our best fits of the EXAFS data are $3.64 \AA$ and $1.93 \AA$, respectively, consistent with the same structure of the active site of oxyhemocyanin $\left(\mathrm{Cu}^{\cdots} \mathrm{Cu}: \sim 3.6 \AA\right.$ and $\left.\mathrm{Cu}-\mathrm{O}: 1.92 \sim 1.94 \AA\right)$ previously reported by Hodgson et al. based on their analysis of EXAFS data. ${ }^{7}$ However, the $\mathrm{Cu}$ "' $\mathrm{Cu}$ distance in the putative $\mathrm{Cu}^{\mathrm{III}}(\mu-\mathrm{O})((\mu-1,2)$-peroxo $) \mathrm{Cu}^{\mathrm{III}}$ species $\mathbf{3}$ is longer than that in a similar $\left(\left[\mathrm{Cu}_{2}\left(\mathrm{XYL}^{-} \mathrm{O}^{-}\right)\left(\mathrm{O}_{2}\right)\right]^{1+}\right.$ species reported by Karlin et al., for which the $\mathrm{Cu}{ }^{\cdots} \mathrm{Cu}$ distance is $3.31 \AA^{8}$

\section{Supplementary Figures}

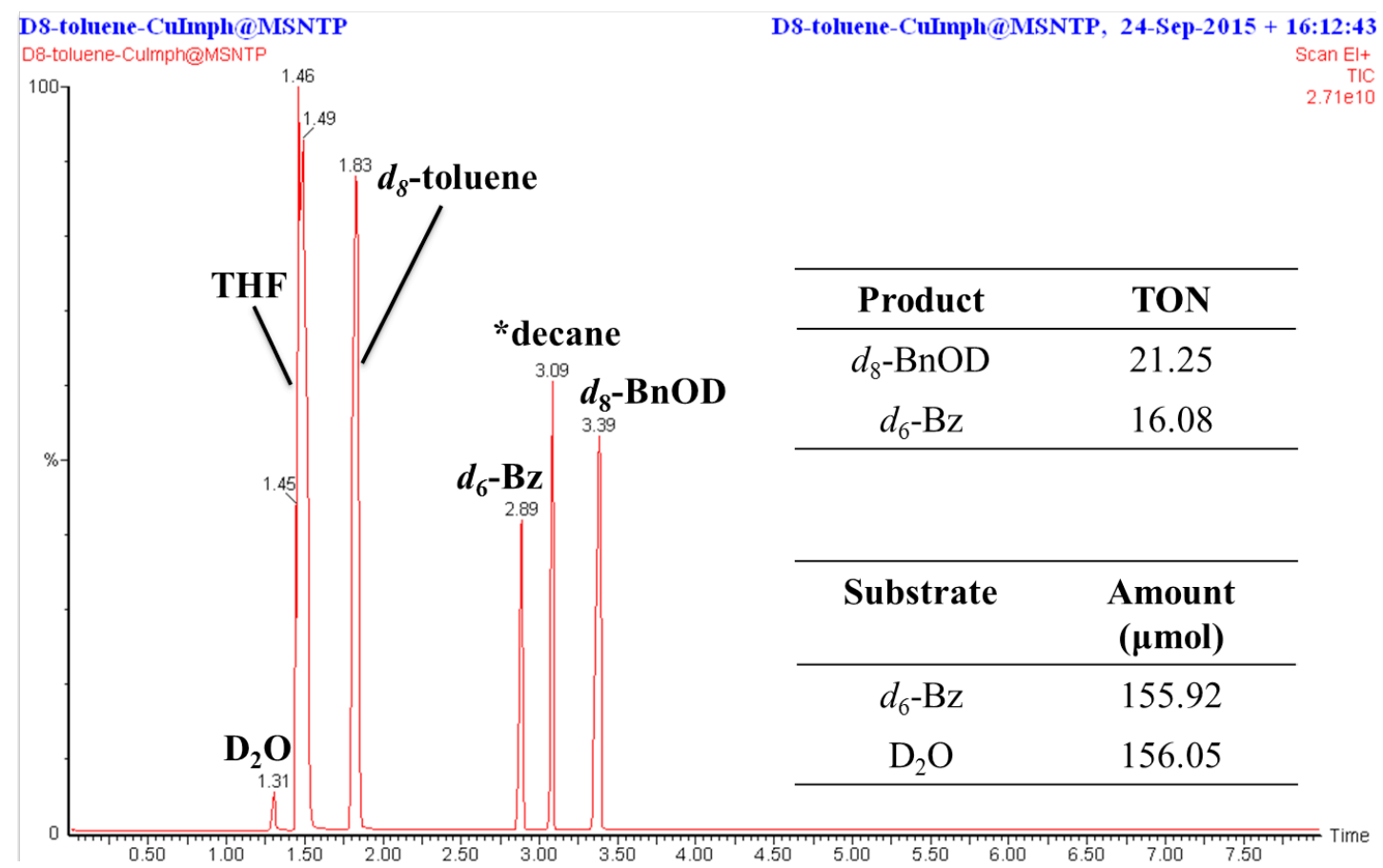

Figure S1. The GC-MS spectra of $d_{8}$-toluene oxidation 12 hours after re-purging $\mathrm{O}_{2}$ into the catalytic system at the end of the single turnover experiment. The amount of 
$\mathrm{D}_{2} \mathrm{O}$ produced is consistent with the stoichiometric quantity of $d_{6}$-benzaldehyde expected for a catalytic reaction with multiple turnovers $\left(d_{6}\right.$-Bz: $155.92 \mu \mathrm{mol}, \mathrm{D}_{2} \mathrm{O}$ : $156.05 \mu \mathrm{mol})$.

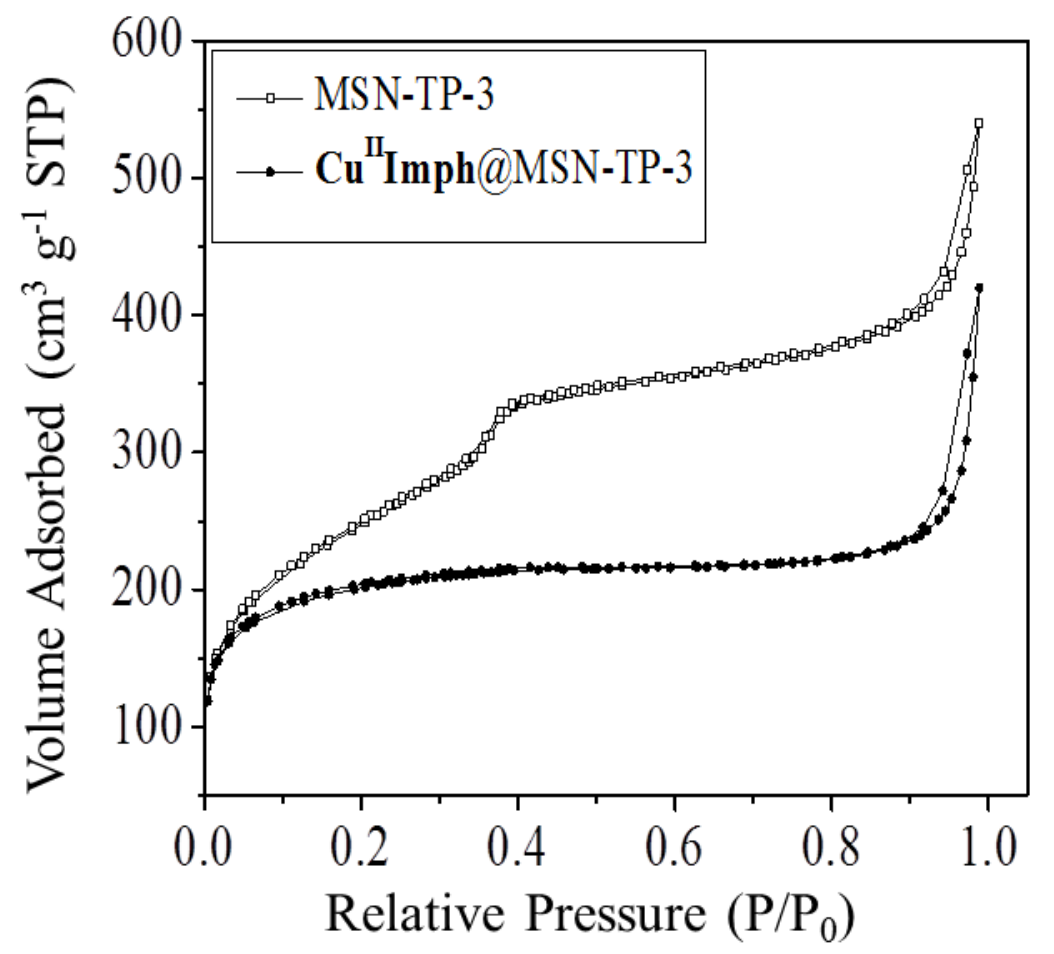

Figure S2. Nitrogen adsorption-desorption isotherms of the MSN-TP-3 and CuIIImph@MSN-TP-3 samples. The significantly reduced mesopore volume in CuIIImph@MSN-TP-3 and the increased micropore contribution are evident from the nitrogen adsorption isotherm. 


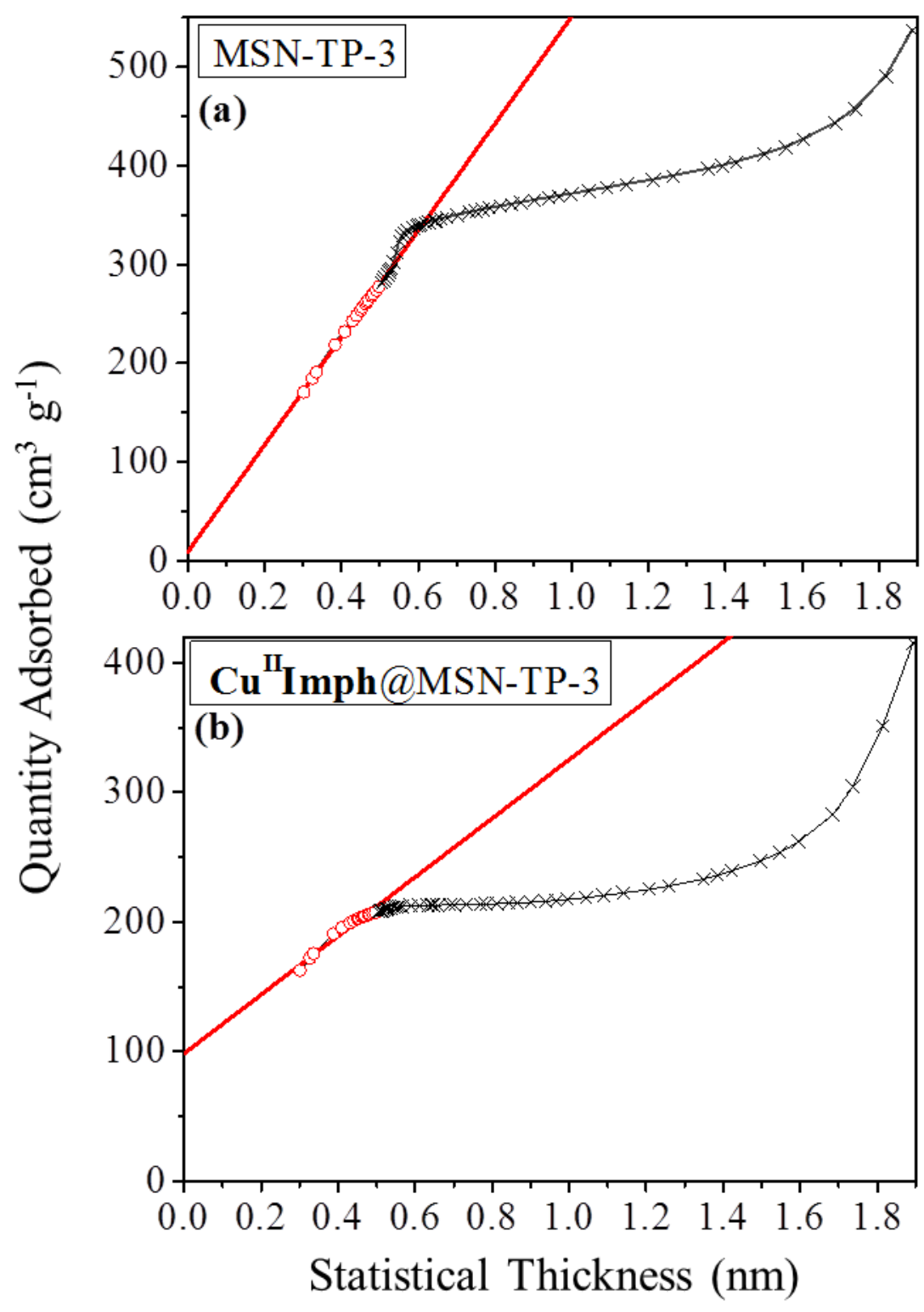

Figure S3. The t-plots of the nitrogen adsorption for (a) the MSN-TP-3, and (b) the CuIIImph@MSN-TP-3 samples. The t-plots show that there are essentially no micropores in the MSN-TP-3 sample, but a substantial portion of the mesopores has been converted into micropores in the Cu-complex loaded $\mathbf{C u} \mathbf{u}^{\mathrm{II}} \mathbf{I m p h} @$ MSN-TP-3 sample. The contributions of the micropore volumes and surface areas obtained from the t-plots for the MSN-TP-3 and CuIIImph@MSN-TP-3 samples are summarized in Table 1 of the main text. 


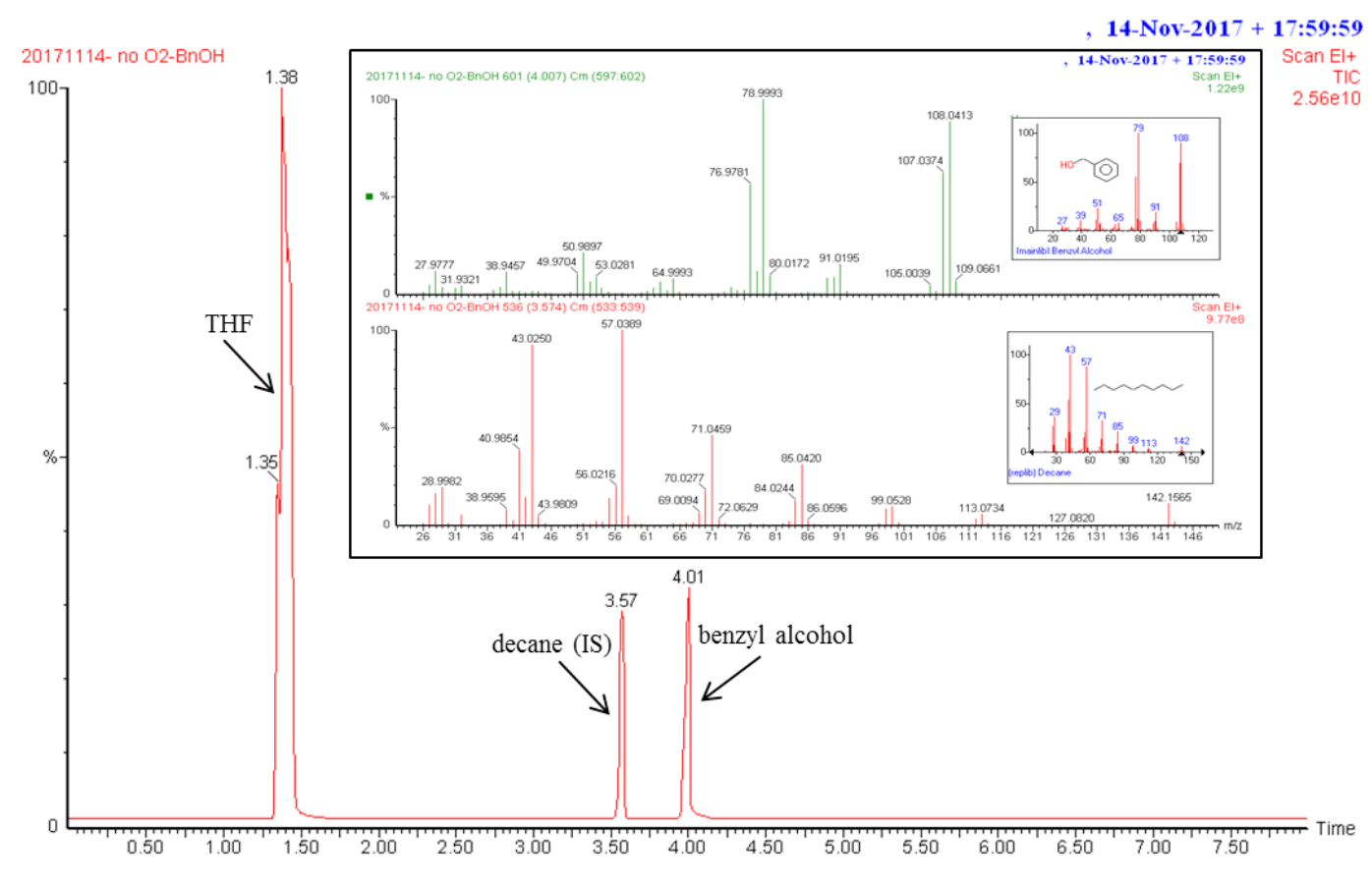

Figure S4. Oxidation of the benzyl alcohol substrate monitored by GC-MS during the incubation period in the single-turnover experiment after an initial 1-h reaction with toluene at room temperature. After the formation of the species 2, the mixture was directly vacuum-dried overnight to remove the solvent, the initial toluene substrate, the product benzyl alcohol, and all the $\mathrm{O}_{2}$ in the sample, including any $\mathrm{O}_{2}$ that might be trapped in the micropores of the Cu-complex-loaded MSN. Then THF was added to the solid sample to obtain a high-quality suspension. Finally, $0.01 \mathrm{ml}$ of the benzyl alcohol (10 equiv.) was added to the system and the reaction was followed for $6 \mathrm{~h}$ at room temperature. There was no evidence of any $\mathrm{Bz}$ produced. 


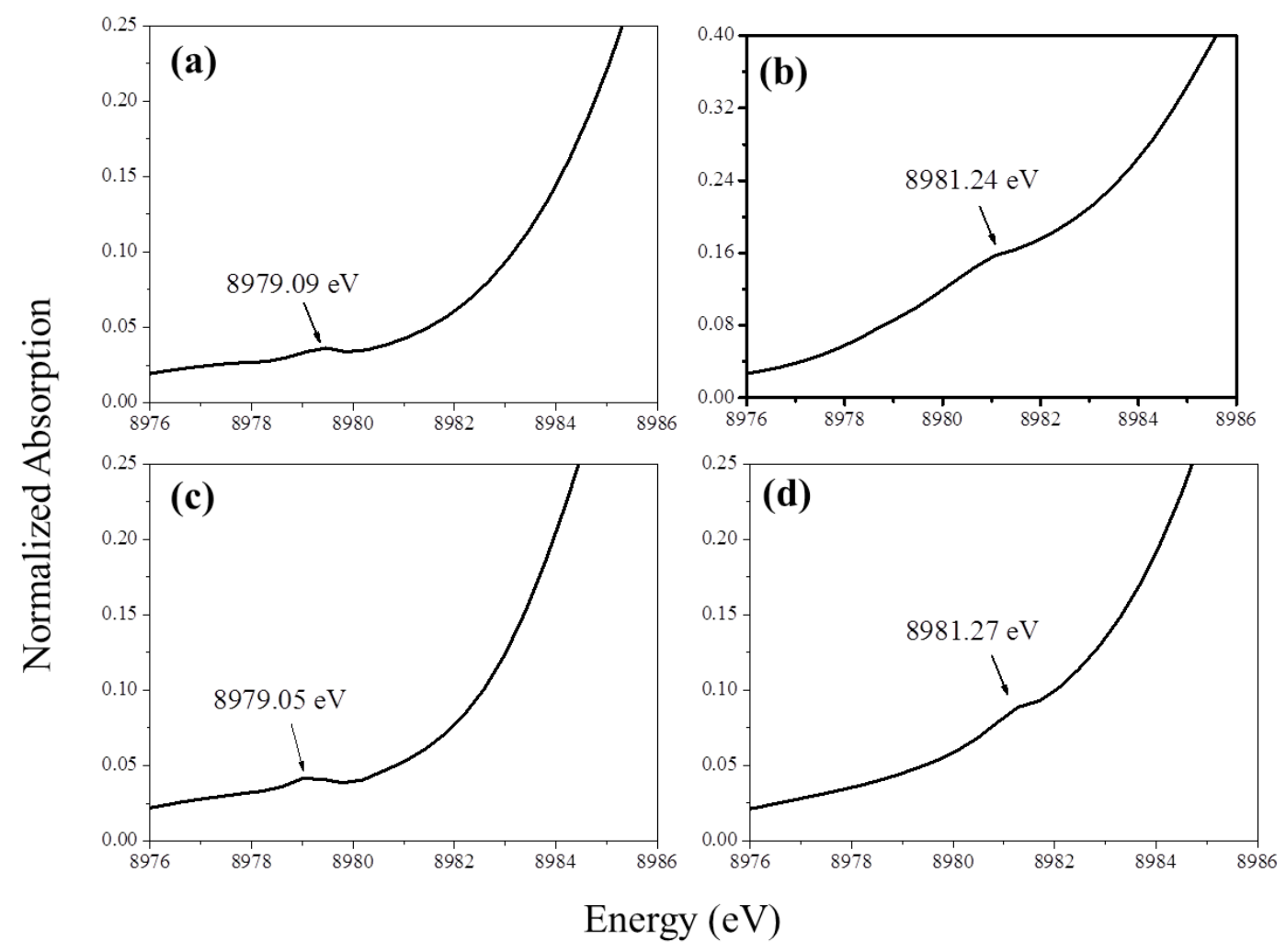

Figure S5. $\mathrm{Cu} K$-edge near-edge spectra (XANES) recorded in the pre-edge region for various species of the dicopper catalyst observed in the CuImph@MSN samples during the oxidation of toluene to benzyl alcohol and benzaldehyde in the single-turnover experiments: (a) $\mathbf{C} \mathbf{u}^{\mathrm{II}} \mathrm{Imph}$ (prior to reduction of the $\mathrm{Cu}^{\mathrm{II}}$ complexes and activation by $\left.\mathrm{O}_{2}\right)$; (b) the $\mathrm{Cu}^{\mathrm{III}}(\mu-\mathrm{O})_{2} \mathrm{Cu}^{\mathrm{III}}$ species $\mathbf{1}$; (c) the $\mathrm{Cu}^{\mathrm{II}}(\mu-\mathrm{O}) \mathrm{Cu}^{\mathrm{II}}$ species 2; and (d) the $\mathrm{Cu}^{\mathrm{III}}(\mu-\mathrm{O})\left(\mu-\mathrm{O}_{2}\right) \mathrm{Cu}^{\mathrm{III}}$ species 3 . 

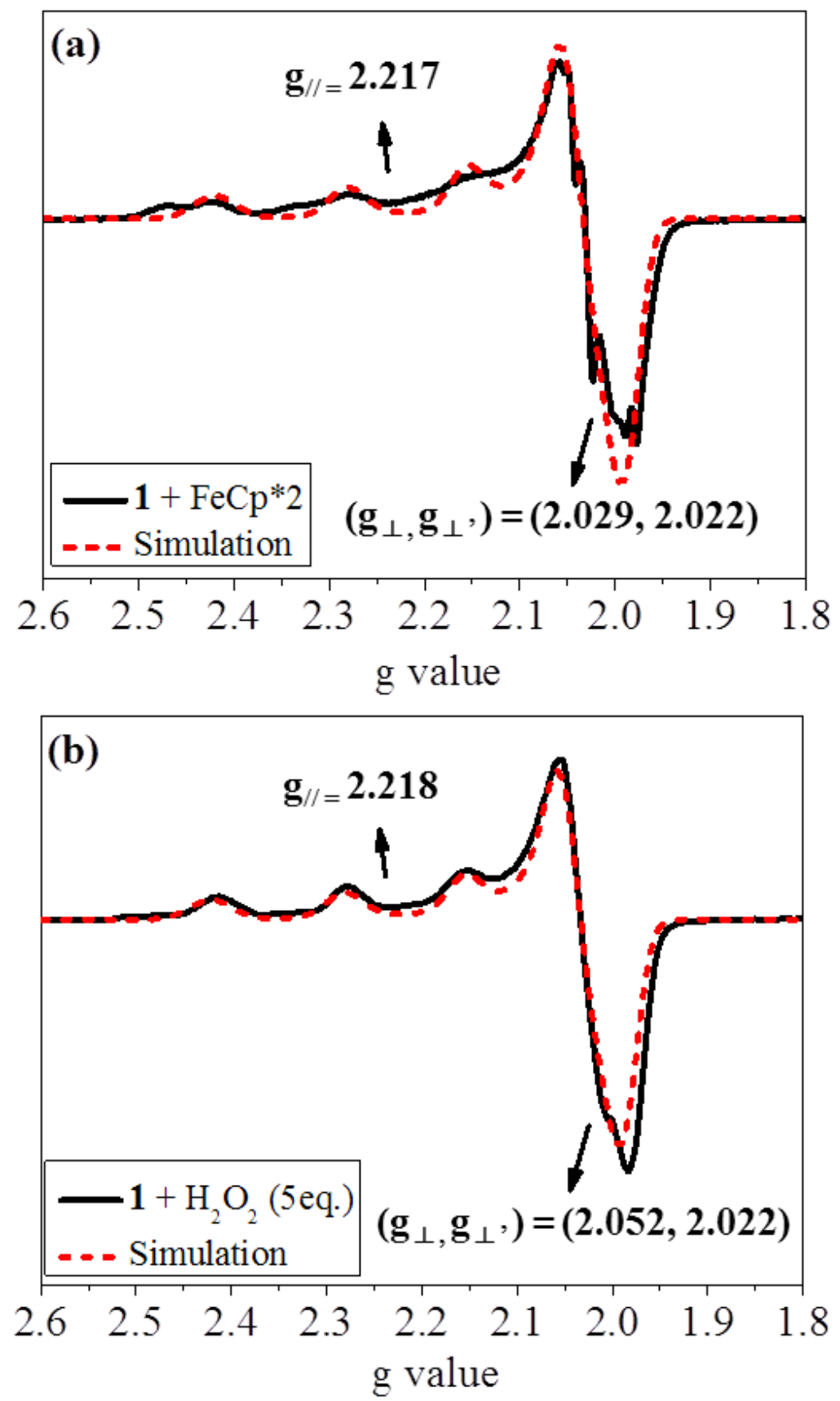

Figure S6. X-band EPR spectra at 77 K. (a) Spectrum of the $\left[\left\{\mathbf{C u} \mathbf{u}^{\text {III Imph }}\right\}_{2}\left(\mu-\mathrm{O}^{2-}\right)_{2}\right]^{2+}$ intermediate (species 1) immobilized in the nanochannels of MSN-TP-3 after reduction by one equivalent of decamethylferrocene ( $\mathrm{FeCp} * 2)$ (black line) and its simulation (red dash line: $\mathrm{g}_{/ /}=2.217 ; \mathrm{g}_{\perp}, \mathrm{g}_{\perp^{\prime}}=2.029,2.022 ; \mathrm{A}_{/ /}=$ $171 \mathrm{G} ; \mathrm{A} \perp, \mathrm{A}_{\perp^{\prime}}=0$ ); and (b) spectrum obtained after reaction of the $\mathbf{C} \mathbf{u}^{\mathrm{II}} \mathbf{I m p h}$ complex in $\mathrm{O}_{2}$-free tetrahydrofuran (THF) with 5 equiv. of $\mathrm{H}_{2} \mathrm{O}_{2}$ in the presence of $\mathrm{Et}_{3} \mathrm{~N}$ (black line) and its simulation (red dash line: $\mathrm{g}_{/ /}=2.218 ; \mathrm{g}_{\perp}, \mathrm{g}_{\perp^{\prime}}=2.052,2.022$; $\left.\mathrm{A}_{/ /}=171 \mathrm{G} ; \mathrm{A} \perp_{\perp}=\mathrm{A}_{\perp^{\prime}}=0\right)$. 

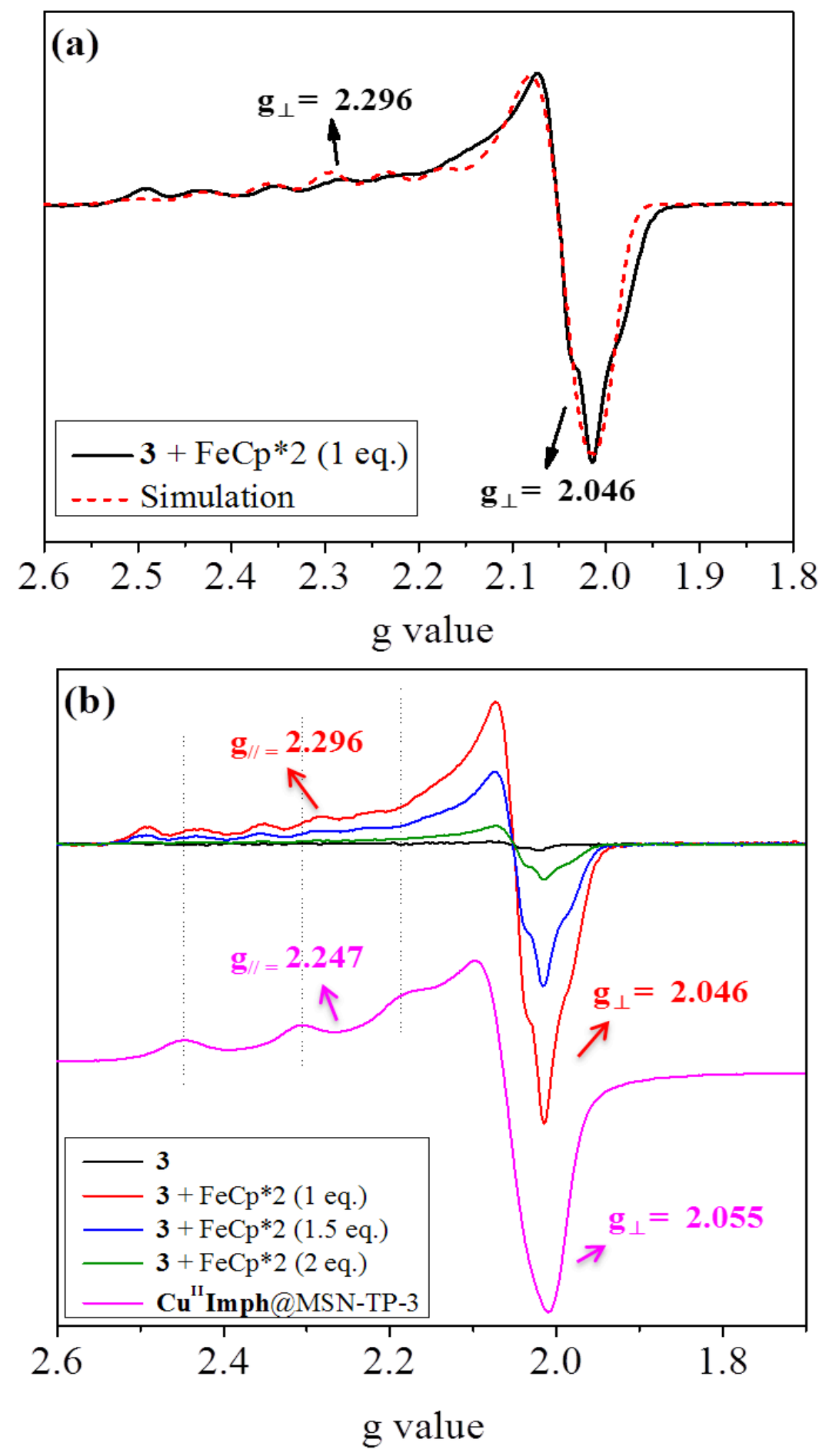

Figure S7. X-band EPR spectra at $77 \mathrm{~K}$ : (a) The simulated spectrum of the $\left[\left\{\mathbf{C u} \mathbf{u}^{\mathrm{II}} \mathbf{I m p h}\right\}\left(\mu-\mathrm{O}^{2-}\right)\left\{\mathbf{C} \mathbf{u}^{\mathrm{I}} \mathbf{I m p h}\right\}\right]^{1+}$ species $\left(\mathrm{g}_{/ /}=2.296, \mathrm{~g}_{\perp}=2.047 ;\right.$ and $\mathrm{A}_{/ /}=80 \mathrm{G}$, $\left.\mathrm{A}_{\perp} \cong 20 \mathrm{G}\right)$. (b) The $\left\{\left[\left\{\mathbf{C u}^{\mathrm{III}} \mathbf{I m p h}\right\}_{2}\left(\mu-\mathrm{O}^{2-}\right)\left(\mathrm{O}_{2}{ }^{2-}\right)\right]^{2+}\right.$ intermediate (species 3) (black line) and the spectrum recorded after reducing species 3 with 1 equiv. of FeCp*2 (red line); 1.5 equiv (blue line); and 2 equiv. (olive line). The EPR spectrum of the

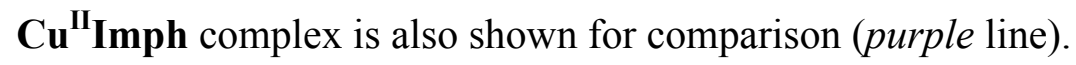




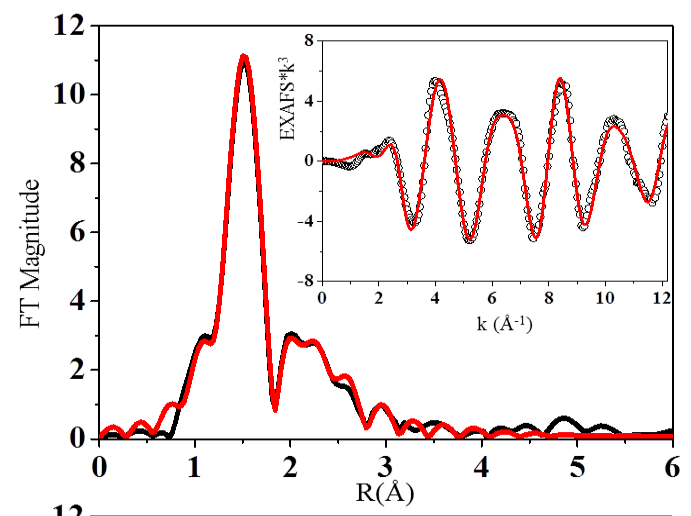

\begin{tabular}{lccc}
\hline \multicolumn{1}{c}{ Fit 1 } & \multicolumn{3}{c}{ Intermediate $\mathbf{1}$} \\
\hline Bond type & $\boldsymbol{N}$ & $\boldsymbol{R}(\boldsymbol{\Lambda})$ & $\boldsymbol{\sigma}^{\mathbf{2}}\left(\boldsymbol{\AA}^{2}\right)$ \\
\hline $\mathbf{C u}-\mathbf{O}$ & 2 & $1.90(6)$ & $0.003(1)$ \\
$\mathbf{C u}-\mathbf{N}{ }^{a}$ & 3 & $1.96(2)$ & $0.005(1)$ \\
$\mathbf{C u}-\mathbf{C}$ & 7 & $3.14(8)$ & $0.003(3)$ \\
$\mathbf{C u}-\mathbf{C u}$ & 1 & $2.64(7)$ & $0.002(3)$ \\
$R_{\text {fit }} 0.035 \%$ & & & \\
\hline
\end{tabular}

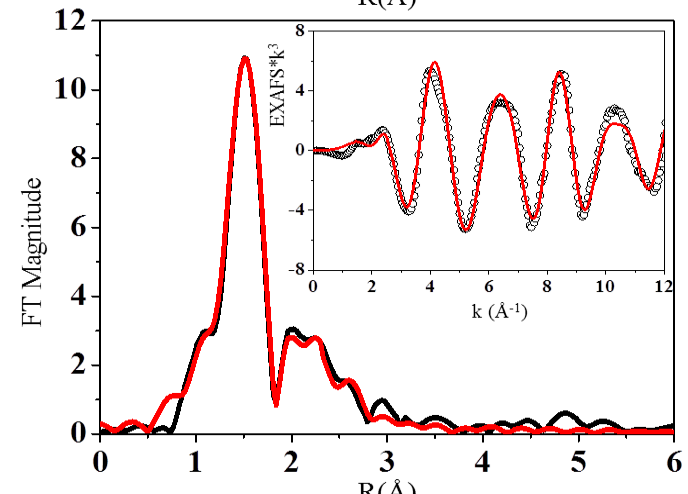

\begin{tabular}{lccc}
\hline \multicolumn{1}{c}{ Fit 2} & \multicolumn{3}{c}{ Intermediate $\mathbf{1}$} \\
\hline Bond type & $\boldsymbol{N}$ & $\boldsymbol{R}(\boldsymbol{\AA})$ & $\boldsymbol{\sigma}^{\mathbf{2}}\left(\boldsymbol{\AA}^{\mathbf{2}}\right)$ \\
\hline $\mathbf{C u}-\mathbf{O}$ & 2 & $1.95(4)$ & $0.003(2)$ \\
$\mathbf{C u}-\mathbf{N}{ }^{a}$ & 3 & $1.97(1)$ & $0.005(6)$ \\
$\mathbf{C u}-\mathbf{C}$ & 7 & $3.14(1)$ & $0.003(8)$ \\
$\mathbf{C u}-\mathbf{C u}$ & 0 & & \\
$R_{\mathrm{fit}} \quad 0.166 \%$ & & & \\
\hline
\end{tabular}

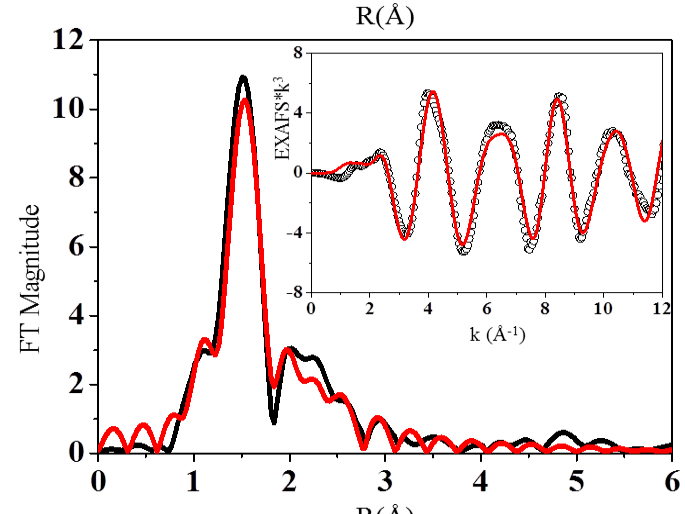

\begin{tabular}{lccc}
\hline \multicolumn{1}{c}{ Fit 3 } & \multicolumn{3}{c}{ Intermediate 1} \\
\hline Bond type & $\boldsymbol{N}$ & $\boldsymbol{R}(\boldsymbol{\AA})$ & $\boldsymbol{\sigma}^{\mathbf{2}}\left(\AA^{\mathbf{2}}\right)$ \\
\hline $\mathbf{C u}-\mathbf{O}$ & 0 & & \\
$\mathbf{C u}-\mathbf{N}{ }^{\boldsymbol{a}}$ & 3 & $1.95(6)$ & $0.001(3)$ \\
$\mathbf{C u}-\mathbf{C}$ & 7 & $3.14(4)$ & $0.010(7)$ \\
$\mathbf{C u}-\mathbf{C u}$ & 1 & $2.67(3)$ & $0.004(3)$ \\
$R_{\text {fit }} \quad 0.231 \%$ & & & \\
\hline
\end{tabular}

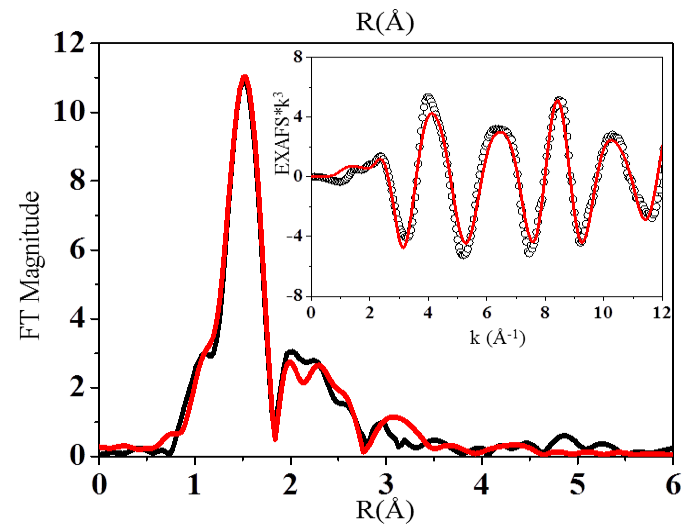

\begin{tabular}{lccc}
\hline \multicolumn{1}{c}{ Fit 4 } & \multicolumn{3}{c}{ Intermediate $\mathbf{1}$} \\
\hline Bond type & $\boldsymbol{N}$ & $\boldsymbol{R}(\boldsymbol{\AA})$ & $\boldsymbol{\sigma}^{\mathbf{2}}\left(\AA^{\mathbf{2}}\right)$ \\
\hline $\mathbf{C u}-\mathbf{O}(\mathbf{1})$ & 1 & $1.90(4)$ & $0.001(3)$ \\
$\mathbf{C u}-\mathbf{N}{ }^{a}$ & 3 & $1.97(2)$ & $0.002(8)$ \\
$\mathbf{C u}-\mathbf{O}(\mathbf{2})^{b}$ & 1 & $3.08(5)$ & $0.003(7)$ \\
$\mathbf{C u}-\mathbf{C}$ & 7 & $3.15(4)$ & $0.004(5)$ \\
$\mathbf{C u}-\mathbf{C u}$ & 1 & $3.73(6)$ & $0.007(6)$ \\
$R_{\mathrm{fit}} 0.286 \%$ & & & \\
\hline
\end{tabular}

Figure S8. $\mathrm{Cu} K$-edge EXAFS data for intermediate $\mathbf{1}$ and fits of the data with (Fits $\mathbf{1}$, 3, and 4) and without (Fit 2) including $\mathrm{Cu}^{*} \mathrm{Cu}$ backscattering; and with possible backscattering from an additional $\mathrm{O}$ in the second coordination sphere $(\mathrm{Cu}-\mathrm{O}(2))$, as might be associated with a ( $\mu-1,2)$-peroxo unit (Fit 4). Left: Fourier transforms of the EXAFS fits. Inset: the $k^{3}$-weighted EXAFS data. Black line: raw data; red line: fitting results. Right: Best-fit parameters used in fitting the $k^{3}$-weighted EXAFS data 
obtained on intermediate $\mathbf{1}$.

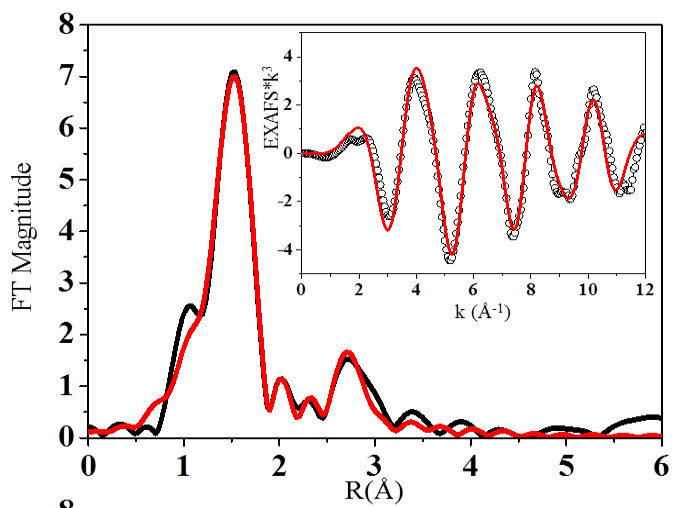

\begin{tabular}{lcll}
\hline \multicolumn{1}{c}{ Fit 1 } & \multicolumn{3}{c}{ Species 2} \\
\hline Bond type & $\boldsymbol{N}$ & $\boldsymbol{R}(\boldsymbol{\AA})$ & $\boldsymbol{\sigma}^{2}\left(\AA^{2}\right)$ \\
\hline $\mathrm{Cu}-\mathrm{O}$ & 1 & $1.89(2)$ & $0.004(7)$ \\
$\mathrm{Cu}-\mathrm{N}{ }^{a}$ & 3 & $1.97(0)$ & $0.003(9)$ \\
$\mathrm{Cu}-\mathrm{C}$ & 7 & $3.14(2)$ & $0.03(3)$ \\
$\mathrm{Cu}-\mathrm{Cu}$ & 1 & $2.84(0)$ & $0.009(6)$ \\
$R_{\mathrm{fit}} 0.040 \%$ & & & \\
\hline
\end{tabular}

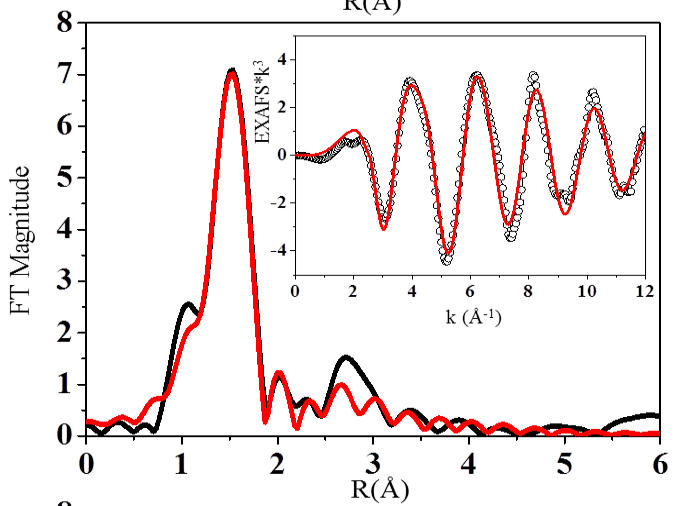

\begin{tabular}{lcll}
\hline \multicolumn{1}{c}{ Fit 2 } & \multicolumn{3}{c}{ Species 2 } \\
\hline Bond type & $\boldsymbol{N}$ & $\boldsymbol{R}(\boldsymbol{\Lambda})$ & $\boldsymbol{\sigma}^{\mathbf{2}}\left(\boldsymbol{\AA}^{\mathbf{2}}\right)$ \\
\hline $\mathrm{Cu}-\mathrm{O}$ & 1 & $1.94(1)$ & $0.003(1)$ \\
$\mathrm{Cu}-\mathrm{N}{ }^{a}$ & 3 & $1.97(6)$ & $0.002(8)$ \\
$\mathrm{Cu}-\mathrm{C}$ & 7 & $3.15(2)$ & $0.04(6)$ \\
$\mathrm{Cu}-\mathrm{Cu}$ & 0 & & \\
$R_{\mathrm{fit}} 0.266 \%$ & & & \\
\hline
\end{tabular}

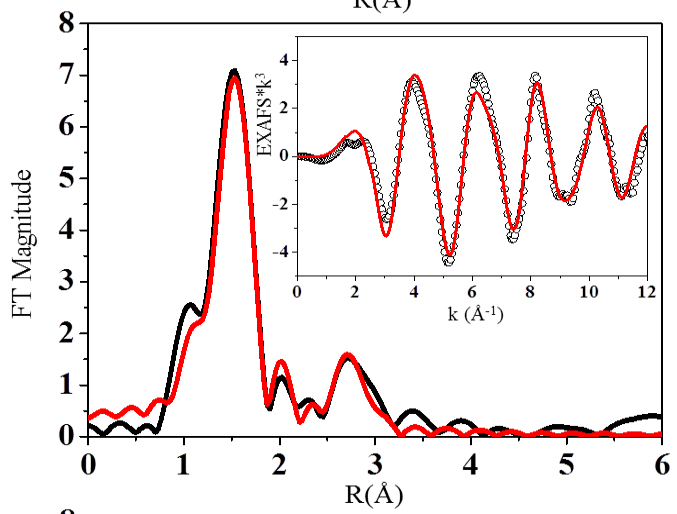

\begin{tabular}{llll}
\hline \multicolumn{1}{c}{ Fit 3 } & \multicolumn{3}{c}{ Species 2} \\
\hline Bond type & $\boldsymbol{N}$ & $\boldsymbol{R}(\boldsymbol{\AA})$ & $\boldsymbol{\sigma}^{2}\left(\AA^{2}\right)$ \\
\hline $\mathrm{Cu}-\mathrm{O}$ & 0 & & \\
$\mathrm{Cu}-\mathrm{N}{ }^{a}$ & 3 & $1.97(7)$ & $0.004(1)$ \\
$\mathrm{Cu}-\mathrm{C}$ & 7 & $3.14(6)$ & $0.03(1)$ \\
$\mathrm{Cu}-\mathrm{Cu}$ & 1 & $2.87(4)$ & $0.01(1)$ \\
$R_{\mathrm{fit}} 0.154 \%$ & & & \\
\hline
\end{tabular}

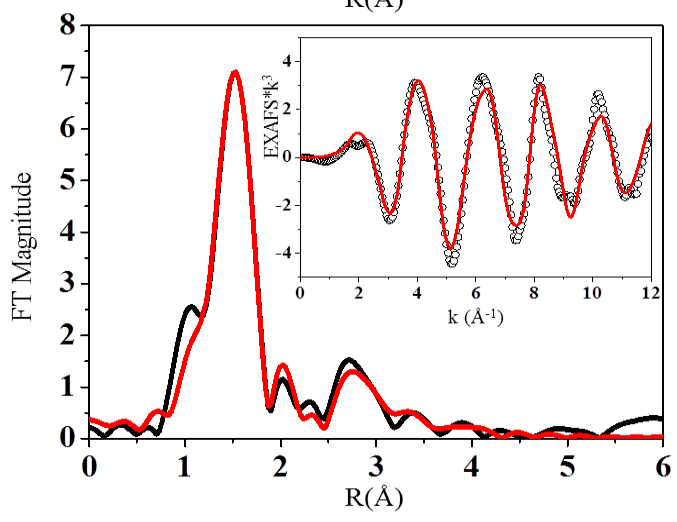

\begin{tabular}{llll}
\hline \multicolumn{1}{c}{ Fit 4 } & \multicolumn{3}{c}{ Species 2} \\
\hline Bond type & $\boldsymbol{N}$ & $\boldsymbol{R}(\boldsymbol{\AA})$ & $\boldsymbol{\sigma}^{\mathbf{2}}\left(\AA^{\mathbf{2}}\right)$ \\
\hline $\mathrm{Cu}-\mathrm{O}(1)$ & 1 & $1.91(3)$ & $0.001(9)$ \\
$\mathrm{Cu}-\mathrm{N}{ }^{a}$ & 3 & $1.98(1)$ & $0.002(7)$ \\
$\mathrm{Cu}-\mathrm{O}(2)^{b}$ & 1 & $3.18(9)$ & $0.001(2)$ \\
$\mathrm{Cu}-\mathrm{C}$ & 7 & $3.15(7)$ & $0.03(6)$ \\
$\mathrm{Cu}-\mathrm{Cu}$ & 1 & $3.83(6)$ & $0.01(6)$ \\
$R_{\mathrm{fit}} \quad 0.217 \%$ & & & \\
\hline
\end{tabular}

Figure S9. $\mathrm{Cu} K$-edge EXAFS data for species 2 and fits of the data with (Fits 1, 3, and 4) and without (Fit 2) including $\mathrm{Cu}^{\cdots} \mathrm{Cu}$ backscattering; without a bridging $\mathrm{O}$ (Fit 3); and with possible backscattering from an additional $\mathrm{O}$ in the second coordination sphere $(\mathrm{Cu}-\mathrm{O}(2))$, as might be associated with a ( $\mu-1,2)$-peroxo unit (Fit 4). Left: 
Fourier transforms of EXAFS fits. Inset: the $k^{3}$-weighted EXAFS data. Black line: raw data; red line: fitting results. Right: Best-fit parameters used in fitting the $k^{3}$-weighted EXAFS data obtained on species 2.

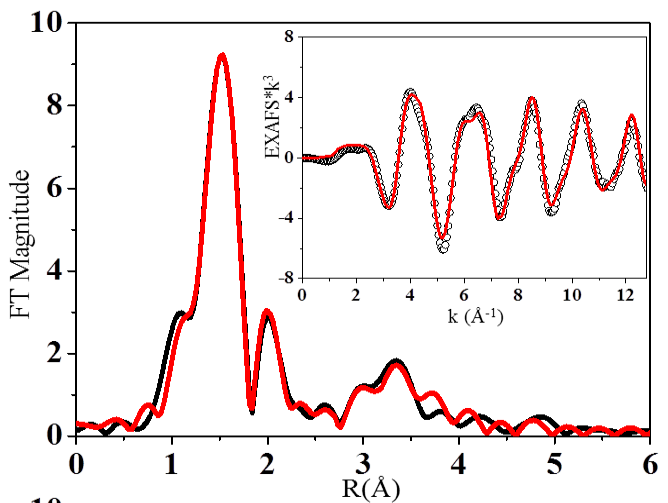

\begin{tabular}{lccl}
\hline \multicolumn{1}{c}{ Fit 1 } & \multicolumn{3}{c}{ Species 3 } \\
\hline Bond type & $\boldsymbol{N}$ & $\boldsymbol{R}(\boldsymbol{\AA})$ & $\boldsymbol{\sigma}^{\mathbf{2}}\left(\boldsymbol{\AA}^{\mathbf{2}}\right)$ \\
\hline $\mathrm{Cu}-\mathrm{O}(1)$ & 2 & $1.93(0)$ & $0.004(6)$ \\
$\mathrm{Cu}-\mathrm{N}{ }^{a}$ & 3 & $1.97(3)$ & $0.002(8)$ \\
$\mathrm{Cu}-\mathrm{O}(2)^{b}$ & 1 & $2.92(7)$ & $0.002(0)$ \\
$\mathrm{Cu}-\mathrm{C}$ & 7 & $3.15(0)$ & $0.008(4)$ \\
$\mathrm{Cu}-\mathrm{Cu}$ & 1 & $3.64(0)$ & $0.003(3)$ \\
$R_{\mathrm{fit}} \quad 0.051 \%$ & & & \\
\hline
\end{tabular}

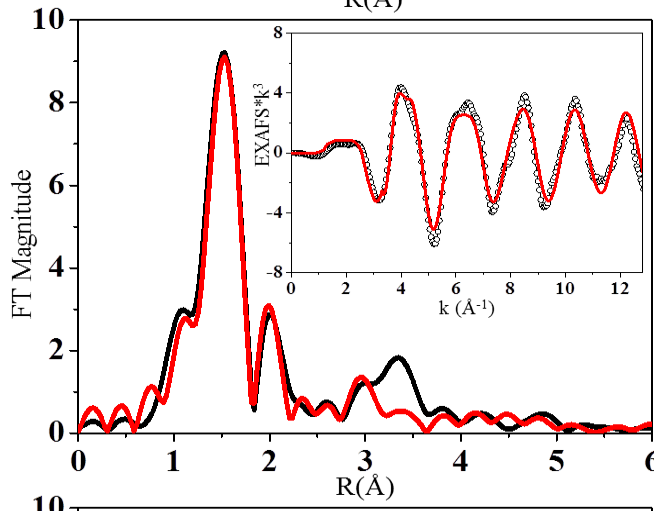

\begin{tabular}{lccl}
\hline \multicolumn{1}{c}{ Fit 2} & \multicolumn{3}{c}{ Species 3 } \\
\hline Bond type & $\boldsymbol{N}$ & $\boldsymbol{R}(\boldsymbol{\AA})$ & $\boldsymbol{\sigma}^{\mathbf{2}}\left(\boldsymbol{\AA}^{\mathbf{2}}\right)$ \\
\hline $\mathrm{Cu}-\mathrm{O}(1)$ & 2 & $2.04(8)$ & $0.004(1)$ \\
$\mathrm{Cu}-\mathrm{N}{ }^{a}$ & 3 & $1.97(2)$ & $0.002(2)$ \\
$\mathrm{Cu}-\mathrm{O}(2)^{b}$ & 1 & $3.09(8)$ & $0.003(9)$ \\
$\mathrm{Cu}-\mathrm{C}$ & 7 & $3.15(7)$ & $0.02(7)$ \\
$\mathrm{Cu}-\mathrm{Cu}$ & 0 & & \\
$R_{\mathrm{fit}} 0.155 \%$ & & & \\
\hline
\end{tabular}

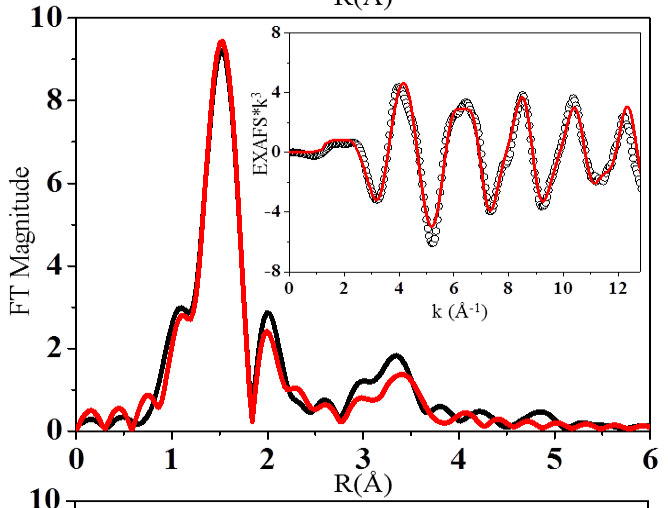

\begin{tabular}{lcll}
\hline \multicolumn{1}{c}{ Fit 3 } & \multicolumn{3}{c}{ Species 3 } \\
\hline Bond type & $\boldsymbol{N}$ & $\boldsymbol{R}(\boldsymbol{\AA})$ & $\boldsymbol{\sigma}^{\mathbf{2}}\left(\boldsymbol{\AA}^{\mathbf{2}}\right)$ \\
\hline $\mathrm{Cu}-\mathrm{O}(1)$ & 1 & $1.95(1)$ & $0.006(9)$ \\
$\mathrm{Cu}-\mathrm{N}{ }^{a}$ & 3 & $1.98(0)$ & $0.001(7)$ \\
$\mathrm{Cu}-\mathrm{O}(2)^{b}$ & 1 & $2.94(6)$ & $0.002(3)$ \\
$\mathrm{Cu}-\mathrm{C}$ & 7 & $3.15(1)$ & $0.02(4)$ \\
$\mathrm{Cu}-\mathrm{Cu}$ & 1 & $3.70(8)$ & $0.005(2)$ \\
$R_{\mathrm{fit}} \quad 0.228 \%$ & & &
\end{tabular}

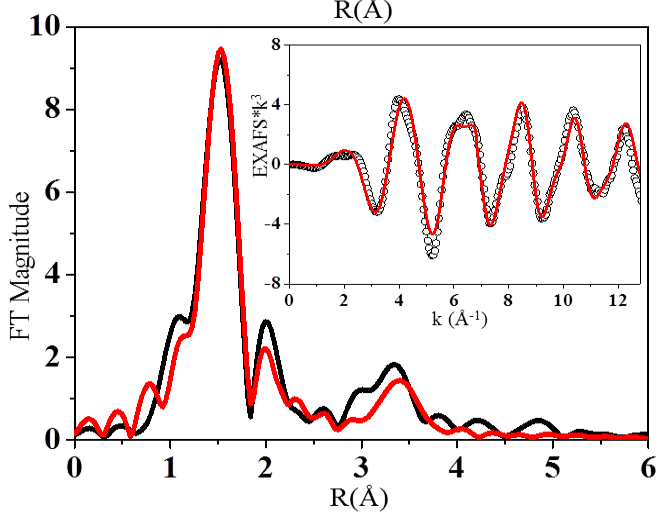

\begin{tabular}{lccl}
\hline \multicolumn{1}{c}{ Fit 4 } & \multicolumn{3}{c}{ Species 3 } \\
\hline Bond type & $\boldsymbol{N}$ & $\boldsymbol{R}(\boldsymbol{\AA})$ & $\boldsymbol{\sigma}^{\mathbf{2}}\left(\boldsymbol{\AA}^{\mathbf{2}}\right)$ \\
\hline $\mathrm{Cu}-\mathrm{O}(1)$ & 1 & $1.90(8)$ & $0.003(1)$ \\
$\mathrm{Cu}-\mathrm{N}{ }^{a}$ & 3 & $1.96(9)$ & $0.001(3)$ \\
$\mathrm{Cu}-\mathrm{O}(2)^{b}$ & 0 & & \\
$\mathrm{Cu}-\mathrm{C}$ & 7 & $3.15(4)$ & $0.01(1)$ \\
$\mathrm{Cu}-\mathrm{Cu}$ & 1 & $3.60(0)$ & $0.005(9)$ \\
$R_{\mathrm{fit}} 0.249 \%$ & & & \\
\hline
\end{tabular}

Figure S10. $\mathrm{Cu} K$-edge EXAFS data for species 3 and fits of the data with (Fit 1, 3, and 4) and without (Fit 2) including $\mathrm{Cu}{ }^{\cdots} \mathrm{Cu}$ backscattering; and without including 
backscattering from the additional $\mathrm{O}$ in the second coordination sphere $(\mathrm{Cu}-\mathrm{O}(2))$ associated with the ( $\mu$-1,2)-peroxo unit (Fit 4). Left: Fourier transforms of EXAFS fits. Inset: the $k^{3}$-weighted EXAFS data. Black line: raw data; red line: fitting results. Right: Best-fit parameters used in fitting the $k^{3}$-weighted EXAFS data obtained on species 3.

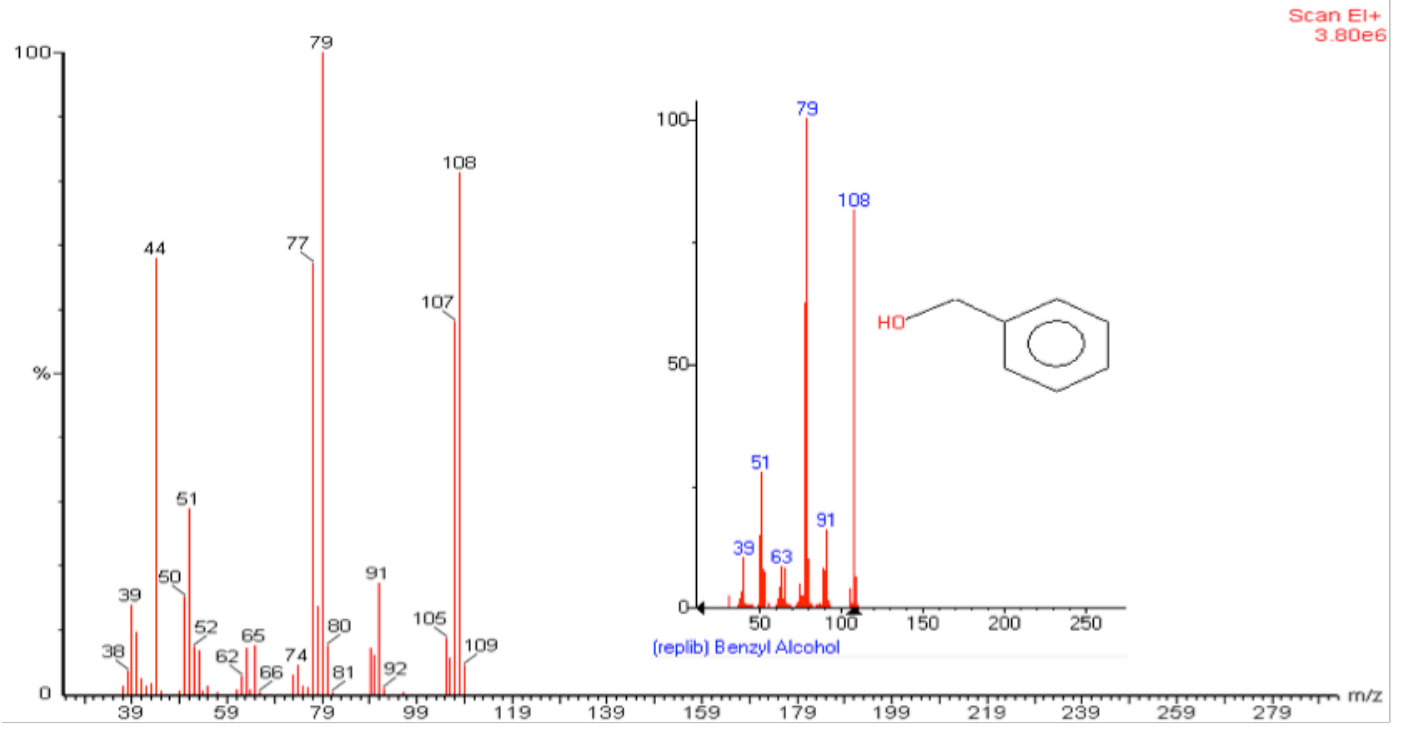

Figure S11. GC-MS spectrum of the benzyl alcohol product $(\mathrm{m} / \mathrm{z}=108)$ produced by oxidation of toluene in a reaction catalyzed by the CuImph@MSN-TP-3 sample at room temperature. Inset: The fitted MS spectrum from the built-in MS database software. 


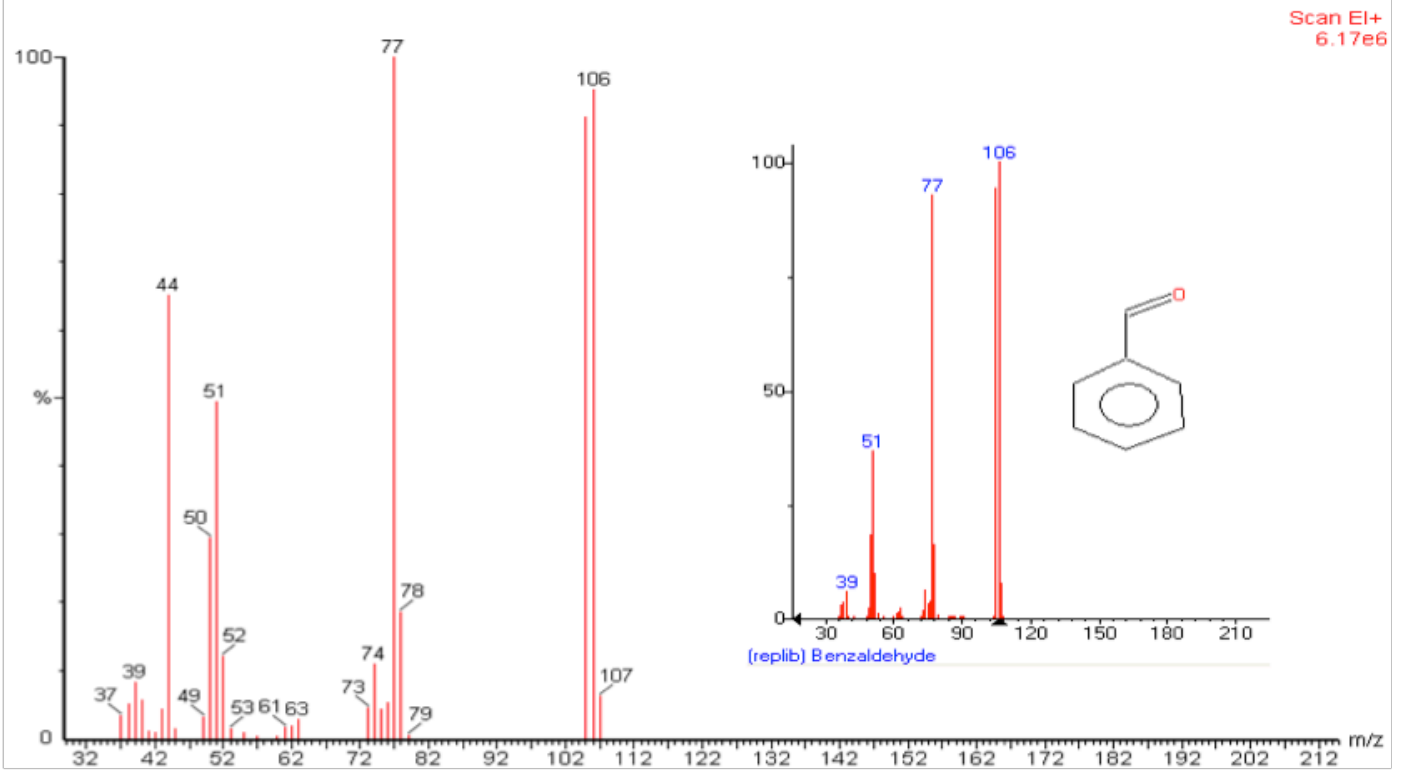

Figure S12. GC-MS spectrum of the benzaldehyde product $(\mathrm{m} / \mathrm{z}=106)$ produced by oxidation of toluene in a reaction catalyzed by the CuImph@MSN-TP-3 sample at room temperature. Inset: The fitted MS spectrum from the built-in MS database software.

D8-toluene-CuImph(1MSNTP

D8-toluene-Culmph@MSNTP 508 (3.387) Cm (506:509)

D8-toluene-CuImph $\%$ MSNTP, 24-Sep-2015 + 16:12:43

Scan El+

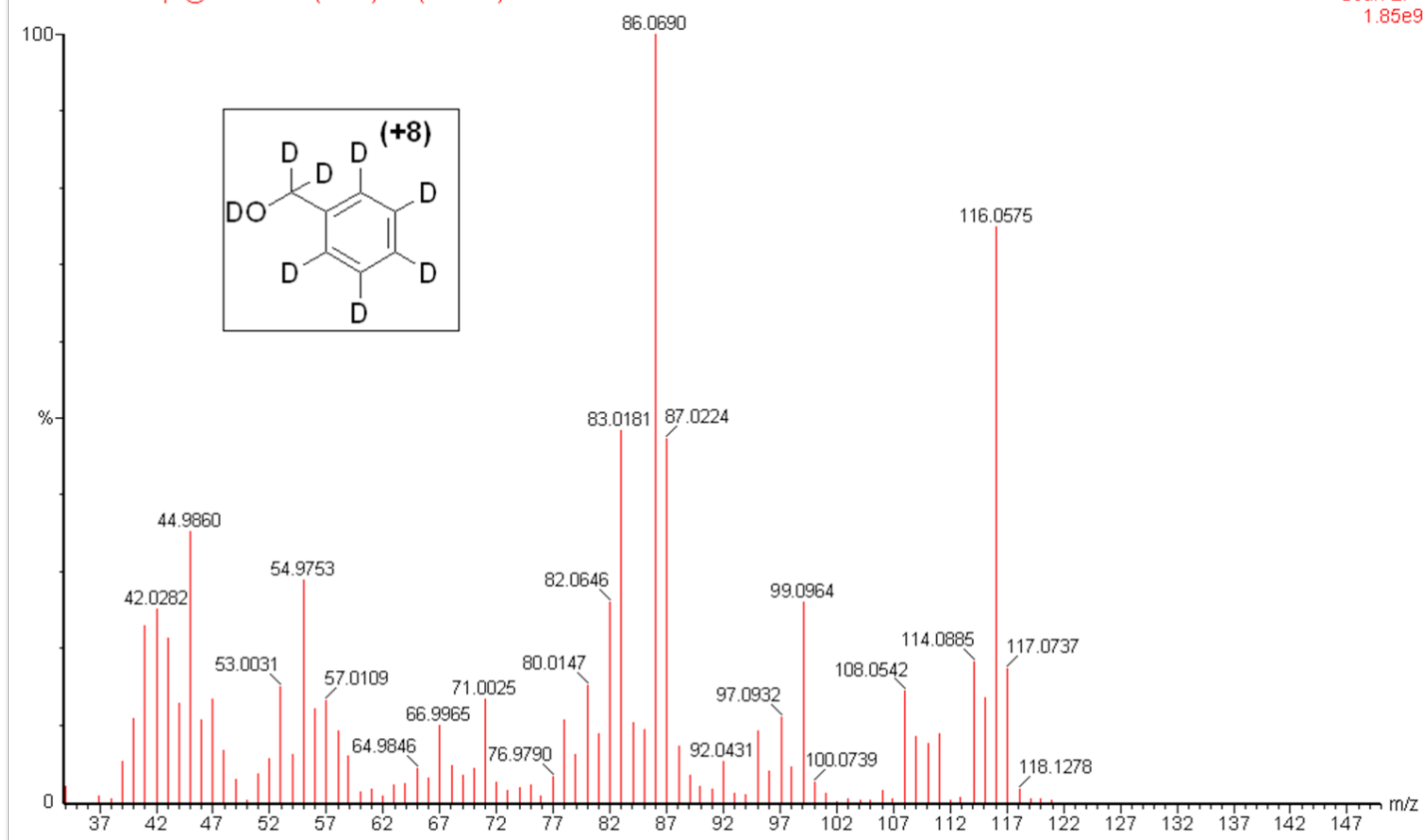

Figure S13. GC-MS spectrum of the $d_{8}$-benzyl alcohol product $(\mathrm{m} / \mathrm{z}=116)$ produced by oxidation of $d_{8}$-toluene in a reaction catalyzed by the CuImph@MSN-TP-3 sample at room temperature. 

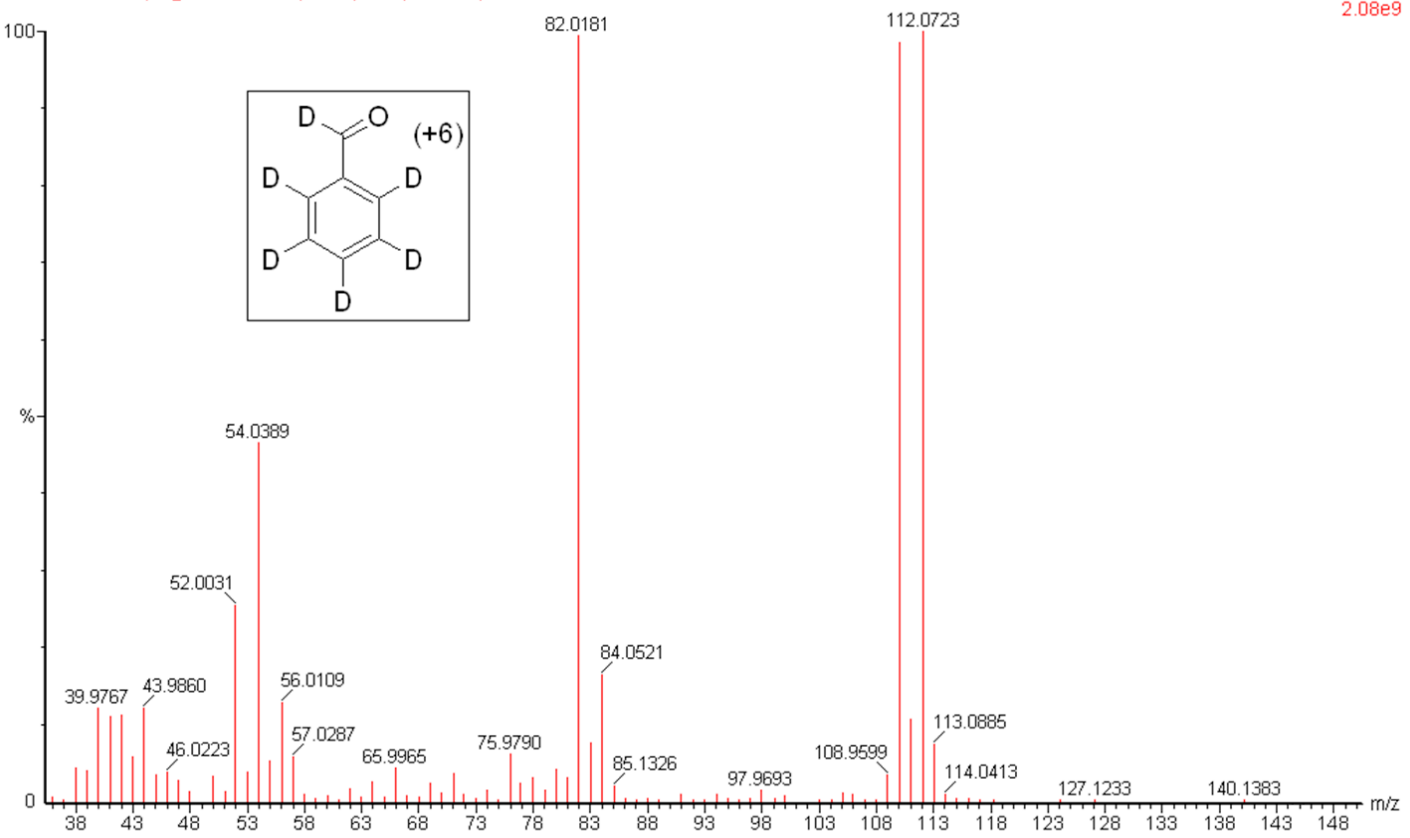

Figure S14. GC-MS spectrum of the $d_{6}$-benzaldehyde product $(\mathrm{m} / \mathrm{z}=112)$ produced by oxidation of $d_{8}$-toluene in a reaction catalyzed by the CuImph@MSN-TP-3 sample at room temperature.

D8-toluene-CuImph $\propto$ MSNTP

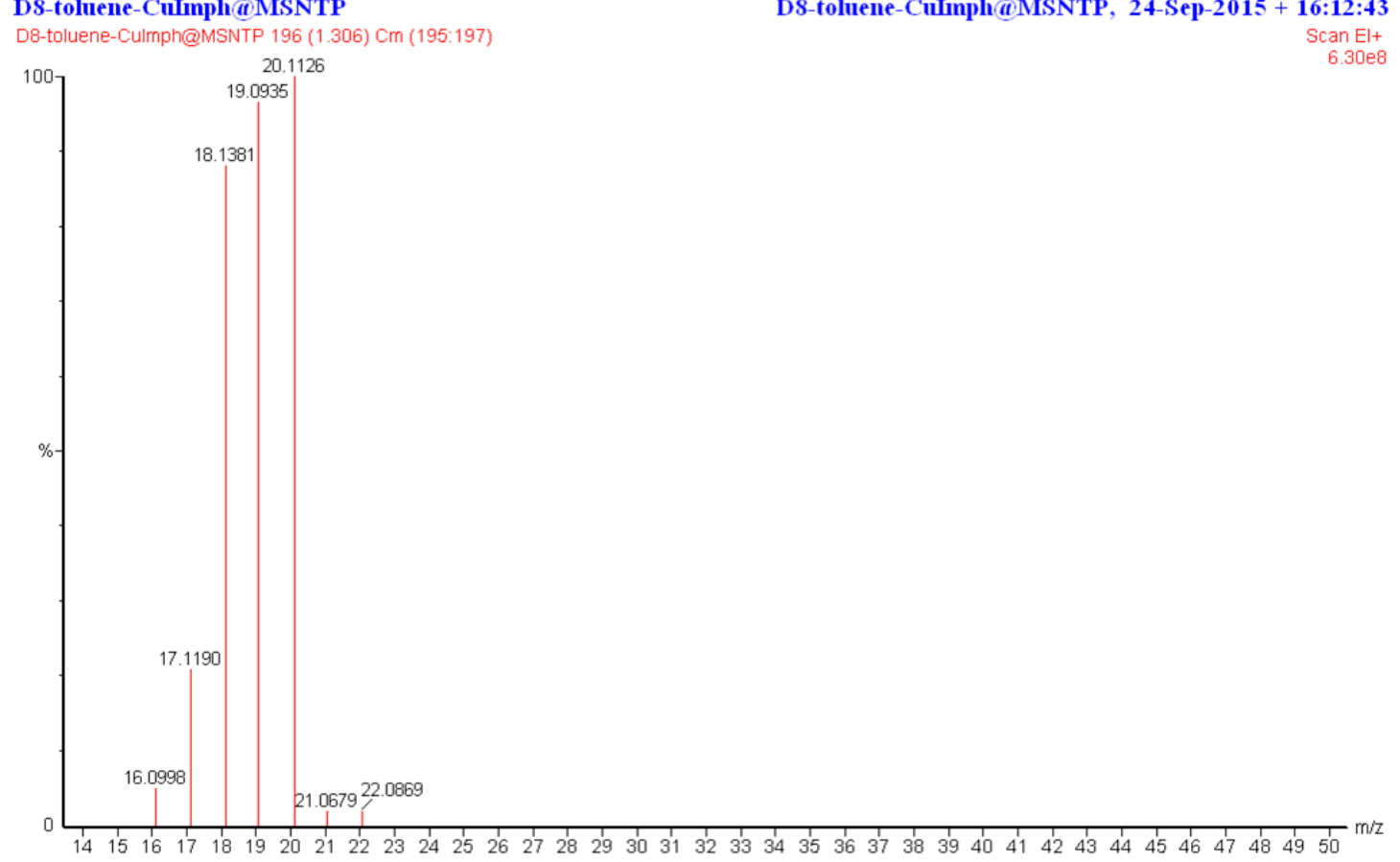

Figure S15. GC-MS spectrum of the $\mathrm{D}_{2} \mathrm{O}$ product $(\mathrm{m} / \mathrm{z}=20)$ produced by oxidation of $d_{8}$-toluene in a reaction catalyzed by the CuImph@MSN-TP-3 sample at room temperature. 

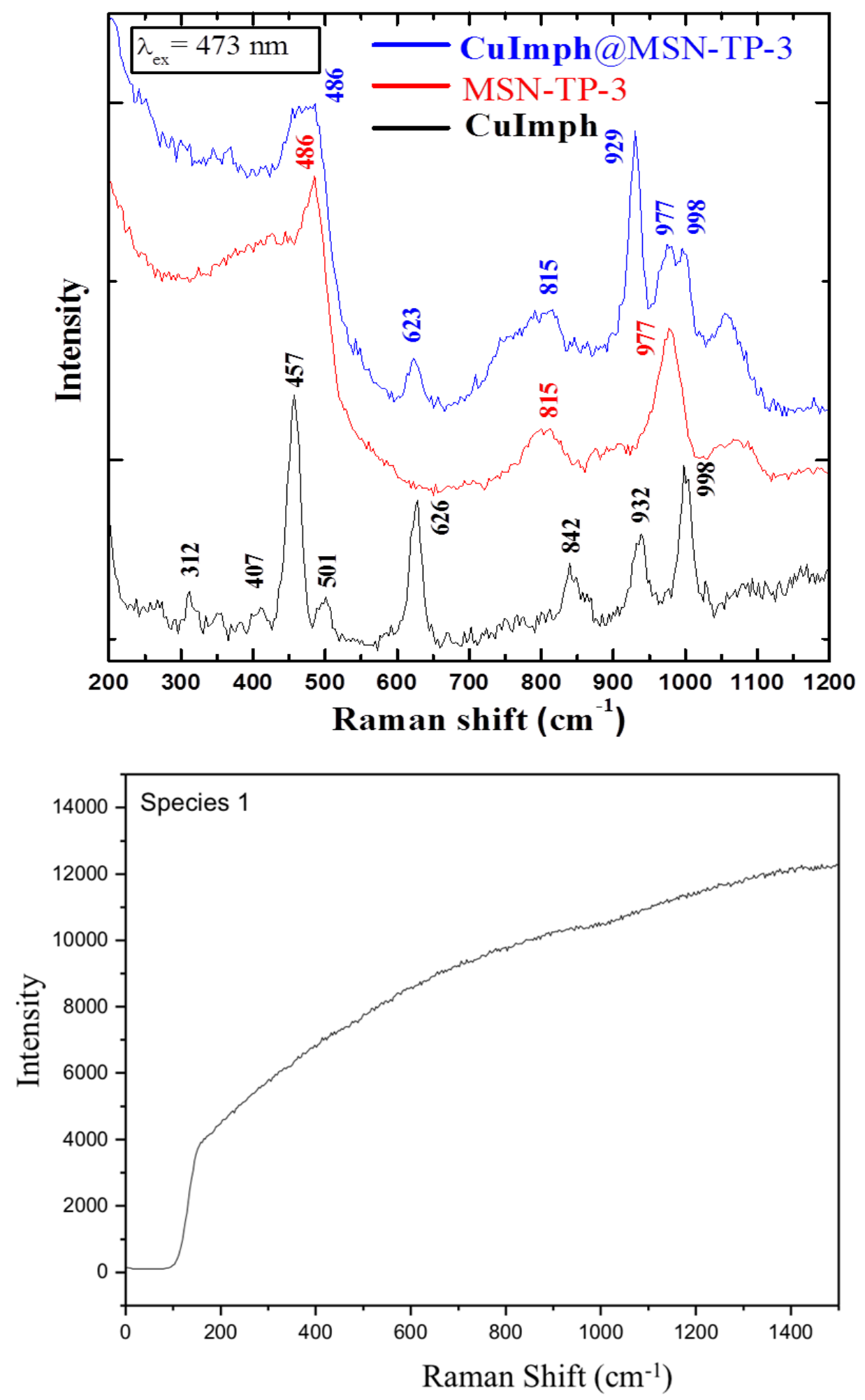

Figure S16. Top: Raman spectra of powder samples of the Cu $\mathbf{C u}^{\mathrm{II}} \mathrm{Imph}$ complex (black); MSN (red); and CuIIImph@MSN (blue), recorded using laser excitation at 473-nm $\left(\lambda_{\mathrm{ex}}=473 \mathrm{~nm}\right)$. Bottom: Raman spectrum of species 1 recorded on the powder using the same blue light at $473 \mathrm{~nm}$ for $20 \mathrm{~s}$ at $77 \mathrm{~K}$. 

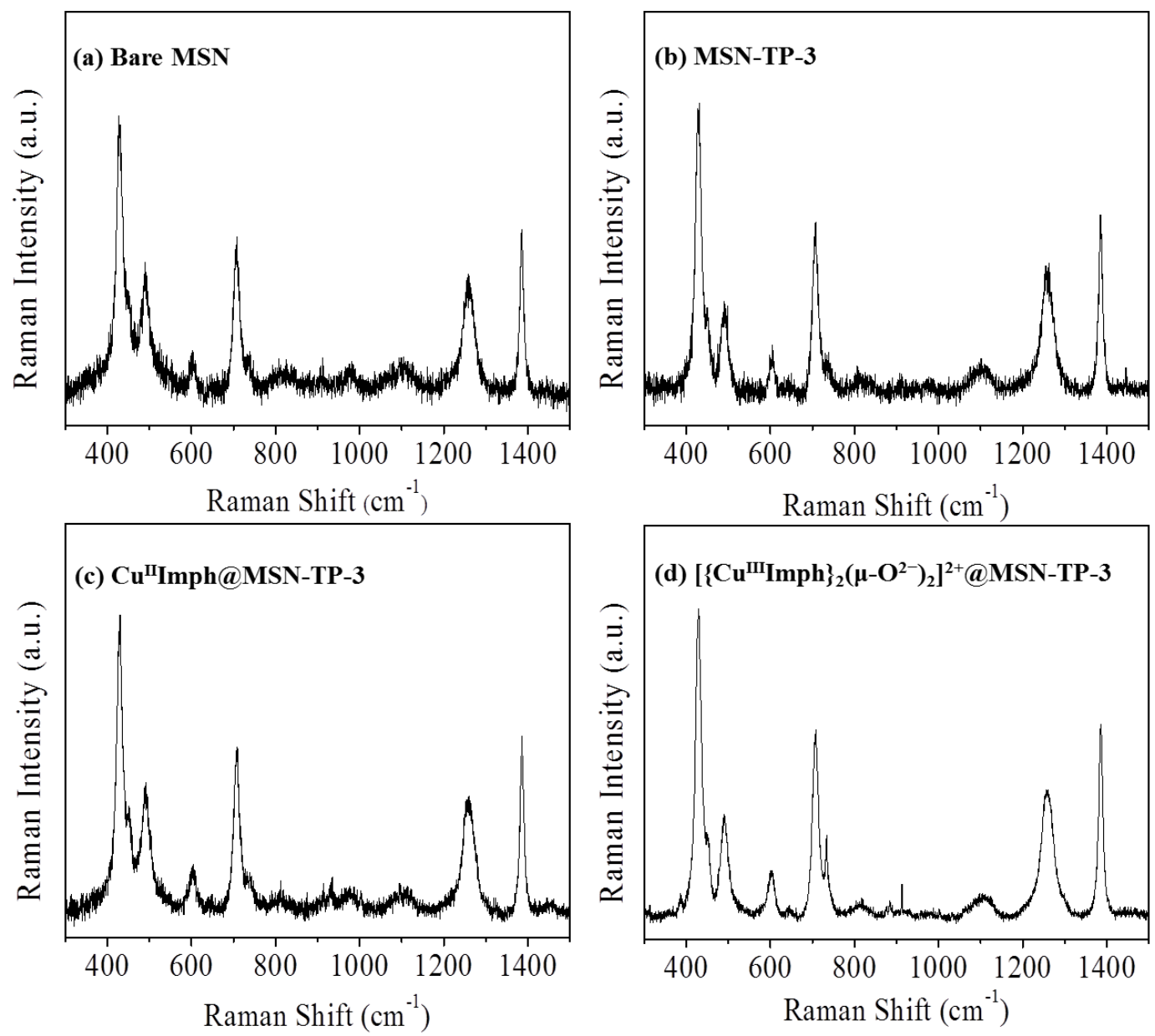

Figure S17. Raman spectra of (a) bare-MSN, (b) MSN-TP-3, and (c)

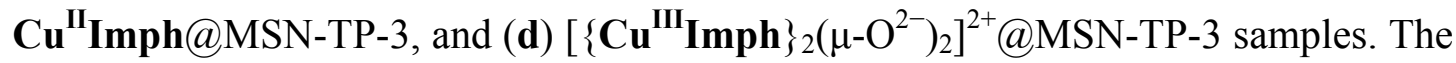
Raman spectra were collected at room temperature on a Horiba Jobin-Yvon LabRAM HR800 instrument using 532-nm excitation of a He-Ne laser. The preparation of species 1 in sample (d) was the same as that used to obtain the UV-Visible spectral measurements. Comparison of panels (a)-(d) reveals no apparent differences among these Raman spectra, exhibiting only the strong non-resonant background scattering from the vibrations of the silica framework of the MSN, especially in the region of the symmetric $\mathrm{Cu}-\mathrm{O}-\mathrm{Cu}$ vibrations. 


\section{References}

1. Liu, C.-C.; Lin, T.-S.; Chan, S. I.; Mou, C.-Y. A room temperature catalyst for toluene aliphatic $\mathrm{C}-\mathrm{H}$ bond oxidation: Tripodal tridentate copper complex immobilized in mesoporous silica. J. Catal. 2015, 322, 139-151.

2. Ravel, B.; Newville, M. ATHENA, ARTEMIS, HEPHAESTUS: data analysis for X-ray absorption spectroscopy using IFEFFIT. J. Synchrotron Radiat. 2005, 12, 537-541.

3. Newville, M. EXAFS analysis using FEFF and FEFFIT. J. Synchrotron Radiat. 2001, 8, 96-100.

4. Newville, M. IFEFFIT: interactive XAFS analysis and FEFF fitting. J. Synchrotron Rad. 2001, 8, 322-324.

5. Mirica, L. M.; Ottenwaelder, X.; Stack, T. D. P. Structure and spectroscopy of copper-dioxygen complexes. Chem. Rev. 2004, 104, 1013-1046.

6. Haack, P.; Kärgel, A.; Greco, C.; Dokic, J.; Braun, B.; Pfaff, F. F.; Mebs, S.; Ray, $\mathrm{K}$.; Limberg, C. Access to a $\mathrm{Cu}^{\mathrm{II}}-\mathrm{O}-\mathrm{Cu}^{\mathrm{II}}$ motif: Spectroscopic properties, solution structure, and reactivity. J. Am. Chem. Soc. 2013, 135, 16148-16160.

7. Co, M. S.; Scott, R. A.; Hodgson, K. O. Metalloprotein EXAFS. A group fitting procedure for imidazole ligands. J. Am. Chem. Soc. 1981, 103, 986-988.

8. Karlin, K. D.; Cruse, R. W.; Gultneh, Y.; Farooq, A.; Hayes, J. C.; Zubieta, J. Dioxygen-copper reactivity. Reversible binding of $\mathrm{O}_{2}$ and $\mathrm{CO}$ to a phenoxo-bridged dicopper(I) complex. J. Am. Chem. Soc. 1987, 109, 2668-2679.

\section{END}

